\title{
Probabilistic seismic hazard assessment for Central Asia
}

\author{
Shahid Ullah ${ }^{1}{ }^{\star}$, Dino Bindi ${ }^{1}$, Marco Pilz ${ }^{1}$, Laurentiu Danciu ${ }^{2}$, \\ Graeme Weatherill ${ }^{3}$, Elisa Zuccolo ${ }^{4}$, Anatoly Ischuk ${ }^{5}$, Natalya N. Mikhailova ${ }^{6}$, \\ Kanat Abdrakhmatov ${ }^{7}$, Stefano Parolai ${ }^{1}$
}

\author{
${ }^{1}$ Helmholtz Center Potsdam - German Research Center for Geosciences, Potsdam, Germany \\ ${ }^{2}$ Swiss Seismological Service (SED), ETH Zurich, Switzerland \\ ${ }^{3}$ GEM Hazard Team, GEM Foundation, Pavia, Italy \\ ${ }^{4}$ European Centre for Training and Research in Earthquake Engineering (EUCENTRE), Pavia, Italy \\ ${ }^{5}$ Tajik Institute of Earthquake Engineering and Seismology, Dushanbe, Tajikistan \\ ${ }^{6}$ Institute of Geophysical Researches, Committee of Atomic Energy of the Republic of Kazakhstan, Almaty, Kazakhstan \\ ${ }^{7}$ Institute of Seismology, Academy of Sciences of the Kyrgyz Republic, Bishkek, Kyrgyzstan
}

\author{
Article history \\ Received October 24, 2014; accepted January 25, 2015. \\ Subject classification: \\ PSHA for Central Asia, Area source model, Smoothed seismicity, Frankel approach, Woo approach, Activity rates, \\ Central Asia earthquake catalog, Seismic Hazard maps.
}

\begin{abstract}
Central Asia is one of the seismically most active regions in the world. Its complex seismicity due to the collision of the Eurasian and Indian plates has resulted in some of the world's largest intra-plate events over history. The region is dominated by reverse faulting over strike slip and normal faulting events. The GSHAP project (1999), aiming at a hazard assessment on a global scale, indicated that the region of Central Asia is characterized by peak ground accelerations for $10 \%$ probability of exceedance in 50 years as high as $9 \mathrm{~m} / \mathrm{s}^{2}$. In this study, carried out within the framework of the EMCA project (Earthquake Model Central Asia), the area source model and different kernel approaches are used for a probabilistic seismic hazard assessment (PSHA) for Central Asia. The seismic hazard is assessed considering shallow (depth $<50 \mathrm{~km}$ ) seismicity only and employs an updated (with respect to previous projects) earthquake catalog for the region. The seismic hazard is calculated in terms of macroseismic intensity (MSK-64), intended to be used for the seismic risk maps of the region. The hazard maps, shown in terms of $10 \%$ probability of exceedance in 50 years, are derived by using the OpenQuake software [Pagani et al. 2014], which is an open source software tool developed by the GEM (Global Earthquake Model) foundation. The maximum hazard observed in the region reaches an intensity of around 8 in southern Tien Shan for 475 years mean return period. The maximum hazard estimated for some of the cities in the region, Bishkek, Dushanbe, Tashkent and Almaty, is between 7 and 8 (7-8), 8.0, 7.0 and 8.0 macroseismic Intensity, respectively, for 475 years mean return period, using different approaches. The results of different methods for assessing the level of seismic hazard are compared and their underlying methodologies are discussed.
\end{abstract}

\section{Introduction}

The region of Central Asia considered in the present study includes the territory of five countries, namely Kazakhstan, Kyrgyzstan, Tajikistan, Uzbekistan and Turkmenistan (see Figures 1 and 2). It is characterized by the presence of the Tien-Shan and Pamir orogenic belts, whose tectonic regime is determined by the convergence of the Indian and Eurasian plates [Molnar and Tapponnier 1975, 1978]. This intra-continental collision region is highly seismic and capable of generating large crustal earthquakes, as evident by the historical seismicity. The aim of the Earthquake Model Central Asia (EMCA) project was the evaluation of the seismic risk in Central Asia, following an end-to-end approach where all the components, from seismic hazard to vulnerability and exposure, were re-assessed and updated.

The seismicity in Central Asia has been studied since the 18th century by Russian and Central Asian scientists [e.g., Kondorskaya and Shebalin 1982, Rautian and Leith 2002, Tatevossian 2004]. The first summary of earthquakes in Central Asia was reported in the catalog of Mushketov and Orlov [1893], based on macroseismic observations. The occurrence of large earthquakes in the area encouraged the development of projects for seismic monitoring. Examples are the installation of a seismic network in Central Asia promoted by the Russian Imperial Geographical Society following the 1887 Verny (Kazakhstan) earthquake, 
which caused a great deal of destruction in the city of Almaty, formerly known as Verny [Mikhailova and Kurskeev 1995], and the seismological instrument area coverage improvement after the 1948 Ashgabat (Turkmenistan) earthquake. Changes in the sensitivity and dynamic range of instruments performed in 1956 and the 1970's led to improved accuracies in location and magnitude estimation [Rautian and Leith 2002], providing more complete data sets for seismological studies and seismic hazard assessment.

Several early studies aiming at seismic hazard assessment were carried out in Central Asia. Early seismic zoning maps of the former USSR and adjacent territories were compiled by Mushketov [1933], in which the expected surface shaking is expressed in terms of isoseismiclines for different intensities, and Gorshkov [1937], who specified five zones of "geological similarity" (respectively for intensities V to IX) extending from areas of former seismic events. Successive seismic zoning maps of the USSR were released in 1957, 1968 and 1978. These maps were also incorporated into national engineering codes. In particular, the general seismic zoning (GSZ) map of 1978 [Bune and Gorshkov 1980] included both boundaries of shaking intensities with zones for intensities from VI to IX on the MSK64 scale [Medvedev et al. 1964] as well as zones of most probable locations of severe earthquakes, differentiated by the maximum expected magnitude, ranging from MLH [Karnik 1968] 6.1 to 8.1. The probability of occurrence of an event was also included, considering return periods of 100,1000 and 10,000 years after the analysis of the recurrence times based on the method of Ryznichenko [1966] and the historical catalog. In the former Soviet Union, a great deal effort was carried out for updating the seismic zoning at different spatial scales, such as detailed seismic zoning (DSZ), valid for the regional level, and seismic microzoning (SMZ) maps, valid at the urban scale. Such maps were characterized not only by their different spatial scales, but also by the way local seismotectonic, ground and other natural conditions were taken into account. In particular, in the SMZ constructed for most of the main cities in Central Asia, the influence of local site amplifications was also accounted for by introducing intensity increments related to local geological conditions. By the end of 1990, SMZ maps showing macroseismic intensity, also considering the effect of soil and topography in a few areas, had been compiled for ten large cities in the USSR [McGuire 2004] including all five capitals of the Central Asian countries.

Between 1991 and 1997, after the collapse of the Soviet Union, a new general seismic zoning (named GSZ97) for Northern Eurasia was developed [Ulomov and the
GSHAP Region 7 Working Group 1999] and was included as a contribution to the GSHAP-Global Seismic Hazard Assessment Program [Giardini 1999]. The hazard map was originally produced for macroseismic intensity and later converted to peak ground acceleration using the Aptikaev and Shebalin [1988] relationship. GSZ-97 was the last seismic zoning that considered the territory of the former Soviet Union as a whole. Starting from the 1990s, seismic hazard, in terms of macroseismic intensities, was re-assessed for many capitals of the now independent countries in Central Asia (for a review, see Nurmagambetov et al. [1999]). As an example, DSZ maps in terms of both macroseismic intensity and peak ground acceleration were produced for the suburbs of Almaty (formerly known as Alma-Ata) [Kyurskeyev et al. 1993] and the probabilistic values of seismic hazard in Almaty were assessed in terms of peak accelerations and intensity [Mikhailova 1996]. For Tashkent (Uzbekistan) and Bishkek (Kyrgyzstan), new probabilistic assessments have been computed by Erdik et al. [2005]. On a larger scale, hazard assessments have been performed for different countries, like Kyrgyzstan [Abdrakhmatov et al. 2003] and Uzbekistan, considering the Cornell [1968] approach.

Within the framework of the EMCA project, new hazard studies have been performed for Central Asia in term of macroseismic intensity. Starting from the distribution of intensity data for earthquakes that occurred in this region since the end of the 19th century, the seismic hazard has been assessed, first following the so-called site-approach [D'Amico and Albarello 2008, Bindi et al. 2012]. Based on this method, the seismic hazard assessment is based on the seismic histories available at different locations, without requiring any a-priori assumption about source zonation. The hazard is computed site by site and is expressed as the probability that the considered site will be shaken with an intensity greater than or equal to the chosen threshold over the assumed exposure time.

In this article, we present the results of the probabilistic seismic hazard assessment of Central Asia obtained following another zone-free approach, namely the smoothed seismicity approach [e.g., Riznichenko 1959], as well as the standard Cornell [1968] approach based on source areas. Regarding the smoothed seismicity, we apply both the method of Frankel [1995], considering also the adaptive kernel proposed by Stock and Smith [2002], and the method proposed by Woo [1996], where the correlation distance is controlled by the magnitude values.

We first introduce the earthquake catalog [Mikhailova et al. 2015, this issue] and the source areas, with their statistical features. Then, different approaches to PSHA based either on point sources (smoothed seismicity) or 


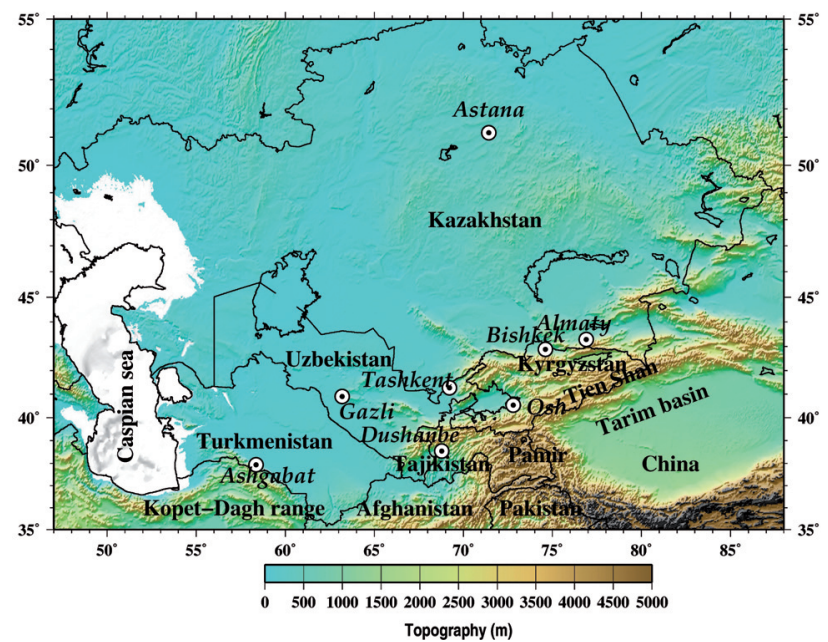

Figure 1. Topographic map of the study area, with the major cities and locations discussed in the text.

a standard zonation are described. Finally, the obtained hazard maps are presented and discussed.

\section{Regional seismotectonics}

The deformation in Central Asia is the result of the India-Eurasia collision, with the Indian Plate migrating northwards, during the Cretaceous and Palaeogene at a rate of $15-20 \mathrm{~cm} /$ year, and slowing down, following its initial collision during Eocene, to its present rate of approximately $5 \mathrm{~cm} /$ year [Patriat and Achache 1984]. A significant amount of this post-collisional lithospheric convergence is accommodated by the convergence of Pamir and Tien Shan, which are two of the major Cenozoic mountain belts in Central Asia. The central and eastern Tien Shan forms an elongated deforming region between two generally stable crustal elements: the Kazakh platform to the north and the Tarim basin to the south. Over a distance of $\sim 1000-1500$ $\mathrm{km}$ north of the Indo-Eurasian plate boundary, the central Tien Shan presently absorbs nearly one-half of the total relative plate convergence of $\sim 45 \mathrm{~mm} /$ year [Abdrakhmatov et al. 1996, Holt et al. 2000]. Focal mechanisms (Figure 14) from moderate and large earthquakes primarily show thrust and reverse faulting with $\mathrm{P}$ axes oriented approximately north-south, consistent with the geodetically measured maximum shortening direction and the overall direction of Indo-Eurasian plate convergence [Tapponnier and Molnar 1979, Nelson et al. 1987, Ghose et al. 1998]. Figures 1 and 2 show the topographic maps of the study region, along with the major cities and locations discussed in this work (Figure 1), and the active faults and tectonic regions (Figure 2).

The deformation in Central Asia is mainly accommodated by reverse faults and intra-mountain basins located far from the boundaries of the major plates [Zubovich et al. 2010], with large fault systems located along the main deformation zones in Central Asia.

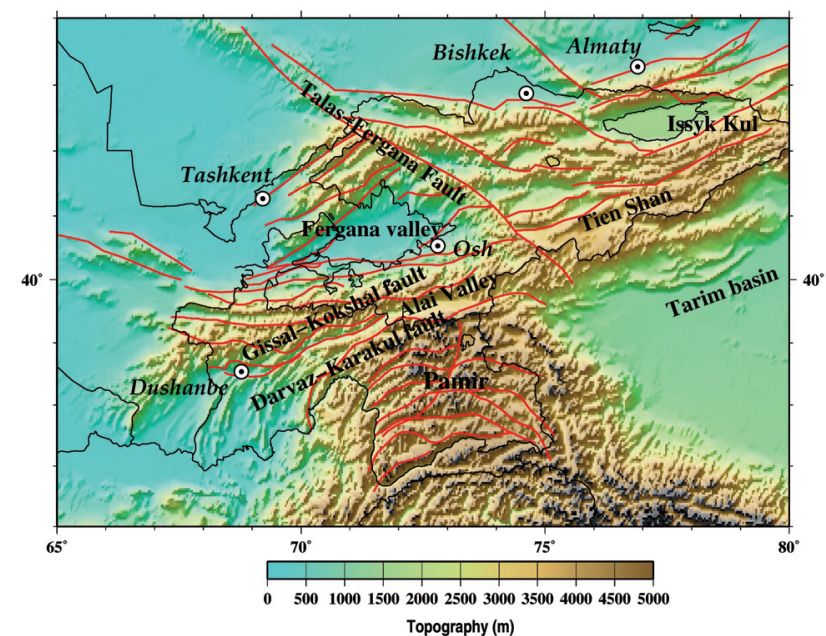

Figure 2. Topographic map of the study area, with the major faults outlined as red lines [Trifonov 1996] and the major tectonic regions.

Amongst these, it is worth mentioning the Pamir thrust located along the Pamir-Tien Shan convergence zone [Schurr et al. 2014]; the right-lateral Talas-Fergana strikeslip fault separating the northeastern and southwestern sectors of Tien Shan, and several fault systems mapped in the northern Tien Shan, such as the Issyk-Ata and ChonKemin faults, which partially accommodate the convergence of the Tarim basin towards the Kazakh platform. Such convergence is absorbed over a region more than $200 \mathrm{~km}$ wide and, although not uniformly distributed, no single predominant fault absorbs the majority of this convergence [Zubovich et al. 2010]. The Pamir has been displaced northwards by about $600 \mathrm{~km}$ with respect to the Tarim basin [Burtman and Molnar 1993] and it is characterized by east-west trending thrust faults and major strike-slip faults flanking the range [Lukk et al. 1995].

The Turan and south Kazak domains (TSK) cover a large area of Central Asia, from the Caspian Sea in the west, to the Tien Shan range in the east, and from the Kopet Dag range in the south, to the Aral Sea in the north. Since the Mesozoic, several continental blocks have accreted to this southern margin of Eurasia, during the successive closures of Paleotethys and Neotethys. Although most of the TSK is nowadays covered by Neogene to Quaternary continental deposits, several discrete Paleozoic basins occur within the south Kazak domain and basins have developed continuously since the Permian over the TSK. These basins provide an almost continuous record of tectonic events on the southwestern margin of Asia since the Mesozoic. However, the timing and boundary conditions controlling basin development are still poorly known. Many paleogeographic reconstructions have inferred back-arc extension in Southwestern Asia during Late Permian to Mesozoic times [Tapponnier et al. 1981, Zonenshain et al. 1990, Dercourt et al. 1993], but few data constrain this setting. Some discrete compressional events have 


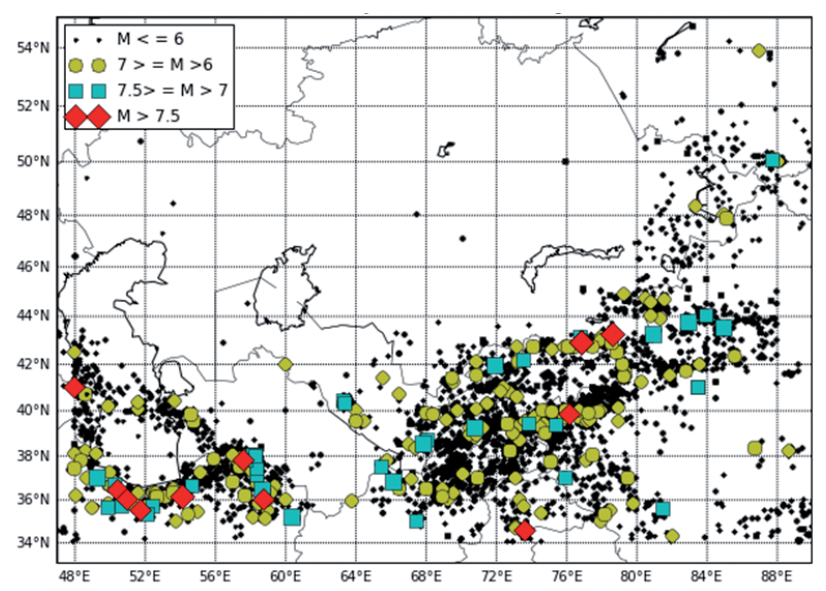

Figure 3. Declustered earthquake catalog from 500 up to 2009 for the study area for events above magnitude 4.0 and a maximum depth of $50 \mathrm{~km}$.

also occurred during the Mesozoic in Southwestern Asia, but their intensity and role in basin development are not well documented [e.g., Otto 1997].

\section{Earthquake catalog and de-clustering}

A complete earthquake catalog is one of the basic components of any PSHA study. The earthquake cata$\log$ for the study area includes about 33,600 earthquakes which have occurred in Central Asia and neighboring areas (Figure 3) over the time period between 1800 and 2009, with 7805 events equal to or above MLH 4.0. About 80 historical earthquakes, which occurred before 1800 up to 500 , are also included in the catalog [Mikhailova et al. 2015].

The catalog is compiled by collecting information from several sources, such as regional bulletins and catalogs being used to compile the catalog from 1991 to 2009. Information about earthquakes occurring before 1990 is mainly taken from Kondorskaya and Ulomov [1996]. The earthquakes sizes are characterized through

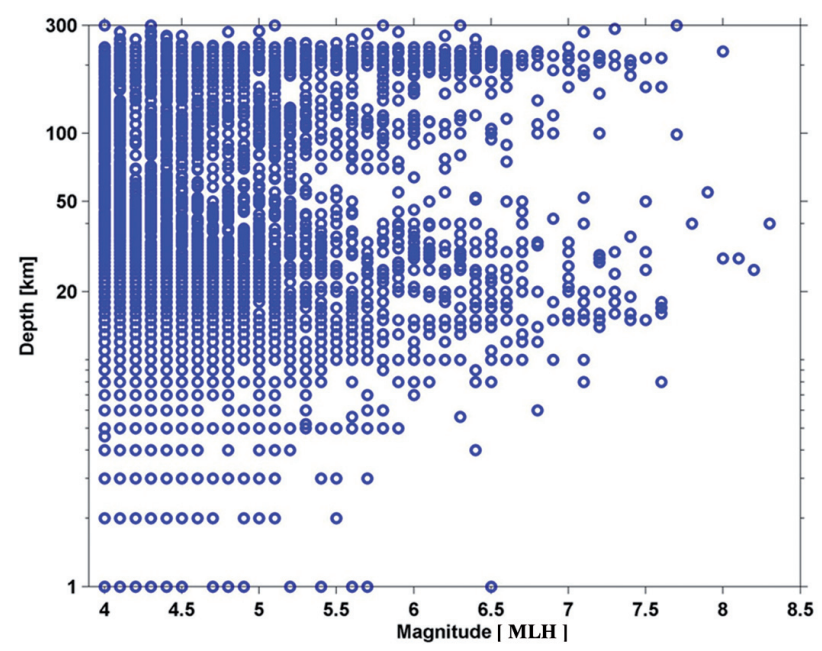

Figure 4. Magnitude-depth distribution of the un-declustered earthquake catalog. different scales, the most common being the body-wave magnitude $\mathrm{mb}$, the surface-wave magnitude MLH [Karnik 1968] and the energy K-class (Rautian et al. [2007] and the references within). The magnitudes in the catalog used in the present study are converted to MLH using empirical regression equations and rounded to the first decimal unit before processing the catalog further for the analysis. In particular, the implemented empirical relations are (Natalia Mikhailova personal communication to the authors):

$$
\mathrm{MLH}=0.47 \mathrm{~K}-1.15
$$

and

$$
\mathrm{MLH}=1.34 \mathrm{mb}-1.89
$$

The catalog contains 60 earthquakes with magnitudes larger than 7, as shown in Figure 3. The depthmagnitude distribution of the un-declustered catalog is shown in Figure 4. The intermediate depth seismicity is mainly located along the Pamir and Hindu-Kush regions. Only earthquakes with focal depths less than 50 $\mathrm{km}$ are considered in this study.

Since PSHA based on the Cornell [1968] approach assumes a Poissonian process of earthquakes, where seismic events are considered temporally independent, the catalog is de-clustered from dependent events. Two de-clustering algorithms are considered, namely the Gardner and Knopoff [1974] method (hereinafter referred to as GK), and the algorithm used in AFTERAN program [Musson 1999] (hereinafter referred to as AF).

The GK method identifies the foreshocks and aftershocks within time and distance windows, fixed accordingly to the magnitude of the event. The events are sorted in order of descending magnitude, and dependent events are identified if they are within the temporal and spatial windows of the largest event. The algorithm can therefore identify foreshocks and aftershocks by considering the windows forwards and backwards in time from the main shock. In the present study, the following magnitude scaling for the time and distance windows are considered: (1) the original windows as proposed by GK [1974]; (2) the modified GK windows as proposed by Grünthal and as reported in Van Stiphout et al. [2012]; (3) the windows proposed by Uhrhammer [1986]. These time and distance windows are summarized below:

GK [1974]:

$\begin{aligned} \text { distance }(\mathrm{km}) & =10^{0.1238 \mathrm{M}+0.983} \\ \text { time }(\text { decimal days }) & =\left\{\begin{array}{l}10^{0.032 \mathrm{M}+2.7389} \text { if } \mathrm{M} \geq 6.5 \\ 10^{0.5409 \mathrm{M}-0.547} \text { otherwise }\end{array}\right.\end{aligned}$ 

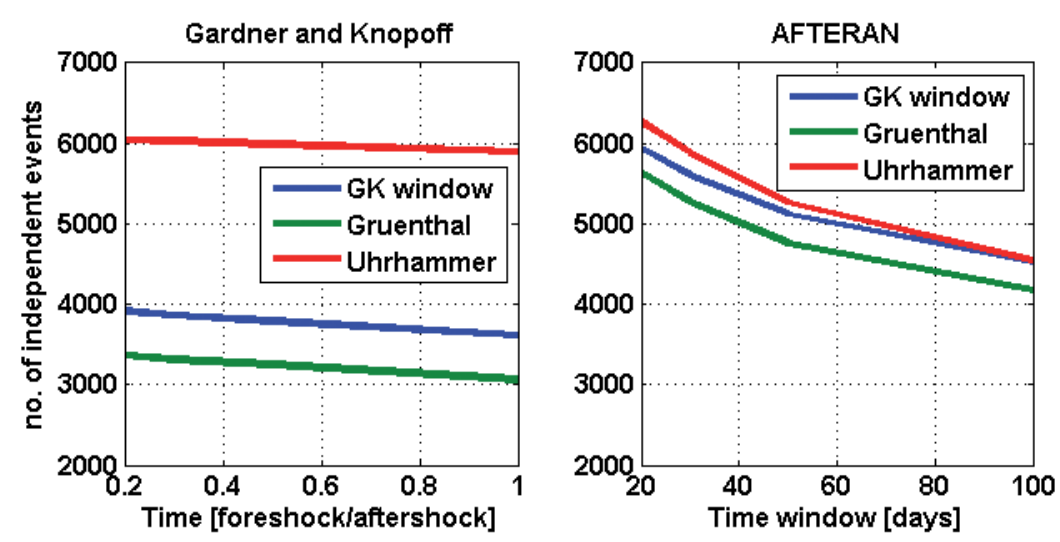

Figure 5. Comparison of declustering algorithms and different time and distance windows. Left side: Declustering using the GK algorithm for varying ratios of foreshocks/aftershocks. Right side: Declustering using the AF algorithm for different lengths of time windows.

Grünthal:

$\begin{aligned} \text { distance }(\mathrm{km}) & =e^{1.77+(0.037+1.02 \mathrm{M})^{2}} \\ \text { time (decimal days) } & = \begin{cases}e^{-3.95+(062+17.32 \mathrm{M})^{2}} & \text { if } \mathrm{M} \geq 6.5 \\ 10^{2.8+0.024 \mathrm{M}} & \text { otherwise }\end{cases} \end{aligned}$

Uhrhammer [1986]:

$$
\begin{aligned}
\text { distance }(\mathrm{km}) & =e^{-1.024+0.804 \mathrm{M}} \\
\text { time }(\text { decimal days }) & =e^{-2.87+1.235 \mathrm{M}}
\end{aligned}
$$

The AF approach is a modification of the GK approach where a moving time window rather than a fixed time window is used. The events are first sorted into their magnitude-descending order. Then, events within fixed distance windows are identified using a moving time window of $\mathrm{T}$ days. The dependent events are declared when they occur both within the distance window and the $\mathrm{T}$ days' time-window. The time window is then moved to the next event, and the process is repeated.

The GK and AF algorithms are used as implemented in the OpenQuake supplementary software Hazard Modeller's Toolkit [Weatherill 2014]. The two algorithms are used with the above mentioned three windows. The GK algorithm is used for different ratios of foreshock and aftershock time and the AF algorithm is used for different lengths of the time windows. The results are summarized in Figure 5. From this figure, it is clear that the Grünthal window identifies more events as being dependent, while the Uhrhammer window identifies fewer. Note that the GK algorithm identifies more dependent events not only in the instrumental part of the catalog, but also those events with magnitudes higher than 7.0 in the historical part of the catalog. In order to retain the maximum number of events and also ensure a Poissonian process, the AF algorithm with a GK distance window and 20 days' time-window is used to de-cluster the catalog. Figure 6 shows the his- togram of dependent events using the AF algorithm. As is clear, most events are in the lower magnitudes and in the most recent instrumental part of the catalog, with about 400 events for magnitude 4. Smaller numbers of events are also identified in the historical part, but are not significant in number.

\section{Seismic hazard approach}

The classical PSHA technique based on CornellMcGuire [Cornell 1968, McGuire 1976] consists of four steps [Reiter 1990]: (1) Identification and characterization of earthquake sources; (2) characterization of magnitude-recurrence distributions; (3) application of the conditional probability to evaluate the ground motion at the site; and (4) calculation of the hazard curves.

Different earthquake sources are defined depending on the available information. An earthquake source can be defined in three forms: a point source, an area source (zonation model) or as a line source (fault model). Since all the faults are not well characterized in the study area, point source and the area source models are used

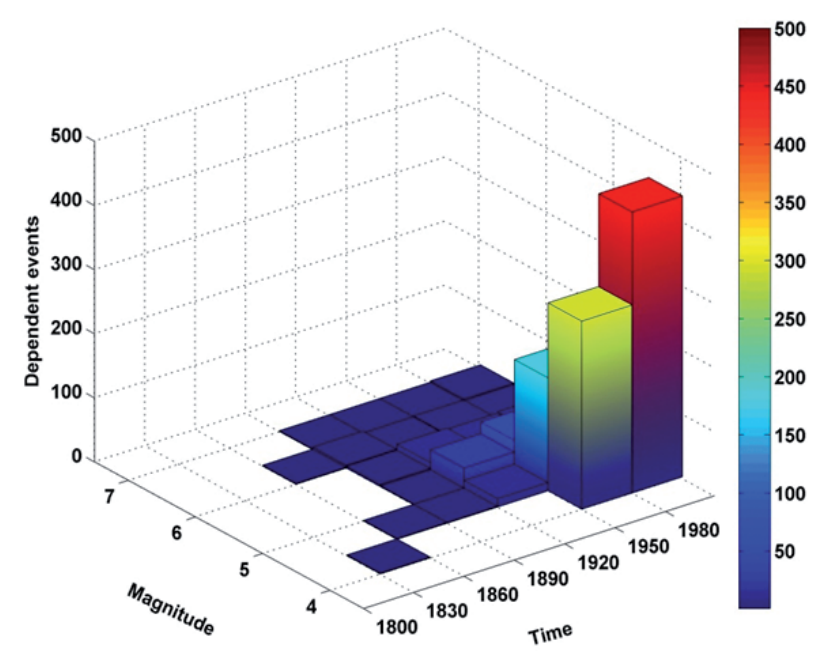

Figure 6. Characteristics of events identified as being dependent using the AFTERAN algorithm with the GK distance window (see Figure 5, right). 

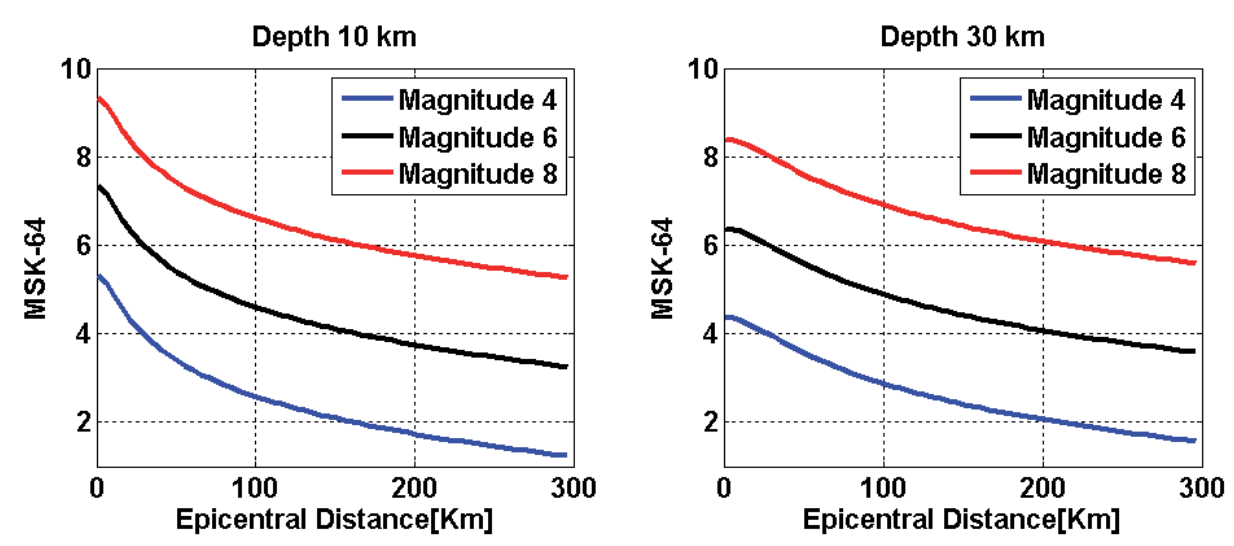

Figure 7. Graphical representation of the IPE used in this study for different magnitudes versus epicentral distances. The left side presents the relationship for a $10 \mathrm{~km}$ hypocentral depth while the right side presents the relationship for a $30 \mathrm{~km}$ hypocentral depth.

in the current study. Point source models using smooth seismicity approaches are described in Section 4.1, while the zonation model is described in Section 4.2.

The GR relationship [Gutenberg and Richter 1944], also called the magnitude-frequency relation, is used to characterize the recurrence relationship for each source:

$$
\log (\mathrm{N})=a-b \mathrm{M}
$$

where $\mathrm{N}$ is the number of events per year for a magnitude $\mathrm{M}$ or larger; $a$ represents the overall activity of the seismic source (log number of events with $M>=0$ ) while $b$ represents the relative distribution of small to large earthquakes. Considering a one year period, $a$ tells us that on average, once per year, an earthquake of magnitude $(a / b)$ or larger occurs. A larger $b$ value represents a region dominated by relatively smaller magnitude earthquakes, while a smaller $b$ value represents a region with relatively higher magnitudes events. The GR parameters estimation for each source is explained

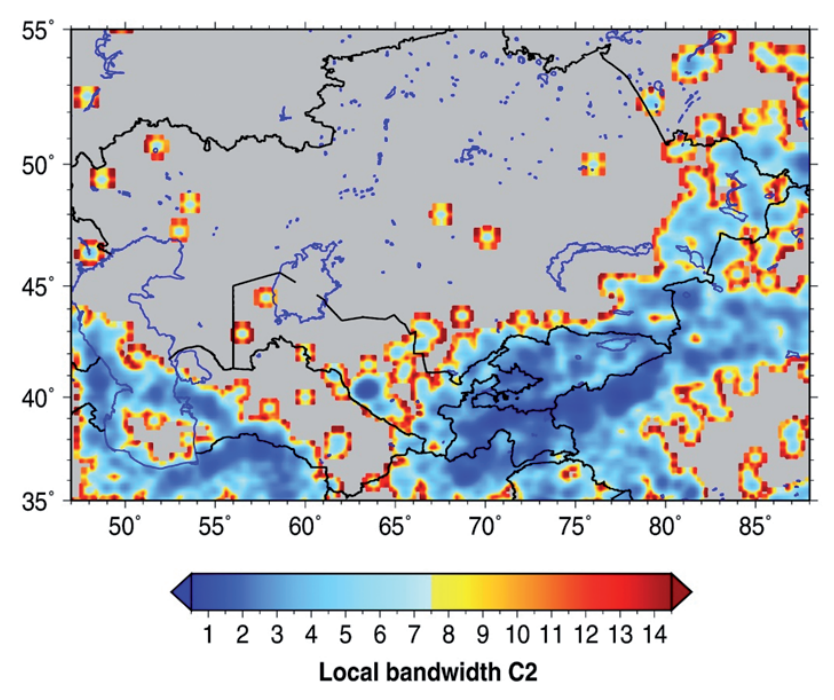

Figure 8. Adaptive correlation distance (local bandwidth) for the study area using the method of Stock and Smith [2002]. The fixed correlation distance $\mathrm{c} 1$ equal to $30 \mathrm{~km}$ is applied. in detail in the source model section.

Intensity prediction equations (IPE) are used in this study to find the magnitude-distance relationships for MSK-64. The choice of an attenuation model is very important for the hazard assessment because of its great influence on the final results. A modified version of the Bindi et al. [2011] IPE for Central Asia is used in this work. This modification is made to consider depth dependency of events in the IPE. The same dataset of Bindi et al. [2011] is used for this modification. In its mathematical form, the IPE derived in this study can be written as:

$$
\begin{aligned}
\mathrm{I}= & 1.007 * \mathrm{M}-2.004 * \log 10(\mathrm{~h})+3.298-2.692 * \\
& 0.5 * \log 10\left(\frac{\mathrm{R}^{2}}{\mathrm{~h}^{2}}+1\right)-0.000423 *\left(\sqrt{\mathrm{R}^{2}+\mathrm{h}^{2}}-\mathrm{h}\right)
\end{aligned}
$$

where the intensity I is expressed in the MSK-64 scale, $\mathrm{R}$ is the epicentral distance and $\mathrm{h}$ is the hypocentral depth. The total standard deviation of Equation (7) is 0.69 . The IPE is represented graphically by Figure 7 for different magnitudes and hypocentral depths.

\subsection{Smooth seismicity approaches}

The smoothing seismicity approach is based on the hypothesis that the past distribution of seismicity provides information about the location of future events.

\subsubsection{Frankel approach [Frankel 1995]}

To apply the smoothed seismicity approach of Frankel [1995], the investigated region is divided into a grid of source points, considering a regular spacing of $0.2 \times 0.2$ degrees. The cumulative number of events in each cell is counted, considering a magnitude threshold equal to 4 . Then, the cumulative number of events for each cell is converted to incremental values using the Herrmann's [1977] formula which requires a $b$ value. Finally, the rates are smoothed spatially using different kernel functions. In particular, we considered: 
(1) A Gaussian kernel function with fixed correlation distance (bandwidth) following Frankel [1995]. In this study, after testing different values, we fixed the correlation distance $\mathrm{c} 1$ to $30 \mathrm{~km}$ and we apply a cut-off at $3 \mathrm{c}_{1}$.

(2) The adaptive kernel function proposed by Stock and Smith [2002], where the correlation distance depends on the local density of earthquakes.

Figure 8 shows the spatial variability of the correlation distance (indicated as c2 in the original work of Stock and Smith [2002]) for the adaptive kernel. c2 represents the additional multiplication factor for $\mathrm{c} 1$ in the adaptive kernel approach. Areas of higher seismicity (see Figure 3) have lower values of local bandwidth as shown by the dark blue color. Lower seismicity areas have larger values of local bandwidth, and are shown by lighter to dark red.

\subsubsection{Woo approach}

The Woo [1996] smoothing approach is based on the concept of fractal geometry and self-organized criticality. For each magnitude interval, the activity rates are determined according to a magnitude-dependent probabilistic smoothing procedure that is applied directly to the epicenters of the earthquake catalog. The contribution of each event to the seismicity of the region is smeared over a distance that is magnitude dependent. Differently from the Frankel [1995] approach, this method does not require the use of a recurrence relationship such as Gutenberg-Richter equation to find the activity rates.

The Woo approach is applied considering a kernel fractal scaling index $\mathrm{n}$ equal to 1.5 . To determine the bandwidth for normalizing epicentral distances (indicated as parameters $\mathrm{c}$ and $\mathrm{d}$ of the exponential function

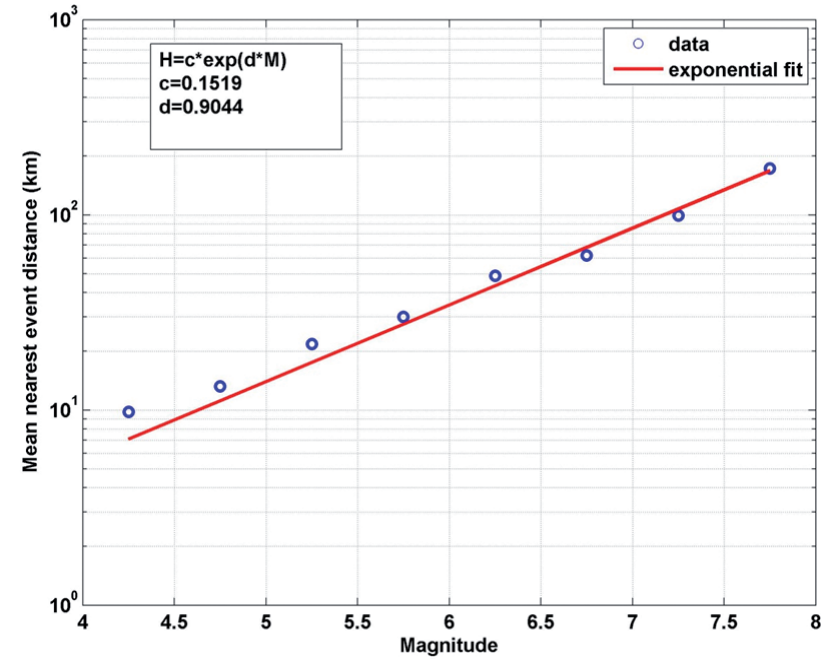

Figure 9. Magnitude-bandwidth relationship to estimate parameters $\mathrm{c}$ and $\mathrm{d}$ at a single site for the Woo [1996] approach.

in the original formulation of Woo [1996]), we followed the approach suggested by Molina et al. [2001], that is: (1) arrange the events in different magnitude bins; (2) for each event within the same magnitude bin, the nearest epicenter distance is determined; (3) the average of all minimum distances within the same magnitude bin is determined; (4) the $c$ and d parameters are estimated using a least squares fit to the observed distance and magnitude. The derivation of the $\mathrm{c}$ and $\mathrm{d}$ parameters for one node of the considering grid is shown in Figure 9. The smoothing distance increases with magnitude in agreement with the observation that smaller events show more spatial clustering than large events. The activity rates are calculated over a regular grid of $0.2 \times 0.2$ degree, assuming a maximum correlation distance of $200 \mathrm{~km}$, and considering magnitude bins 0.5 units wide. The Woo approach also accounts for the uncertainties

\begin{tabular}{|c|c|c|c|c|c|c|c|c|c|}
\hline \multirow{2}{*}{ Super zone } & \multicolumn{9}{|c|}{ Magnitude bins } \\
\hline & 4.25 & 4.75 & 5.25 & 5.75 & 6.25 & 6.75 & 7.25 & 7.75 & 8.25 \\
\hline Whole catalog & 1956 & 1932 & 1931 & 1920 & 1890 & 1837 & 1837 & 1795 & 1795 \\
\hline 1. Iranian block & 1960 & 1928 & 1922 & 1885 & 1885 & 1820 & 1820 & 1820 & 1820 \\
\hline 2. Kazakh block & -- & -- & -- & -- & -- & -- & -- & -- & -- \\
\hline 3. Kazakh block & -- & -- & -- & -- & -- & -- & -- & -- & -- \\
\hline 4. Tajik-Afghan block & 1958 & 1950 & 1902 & 1900 & 1900 & 1900 & 1900 & 1900 & 1900 \\
\hline 5. Turan block & 1975 & 1975 & 1930 & 1930 & 1930 & 1930 & 1930 & 1930 & 1930 \\
\hline 6. Pamir-Hindukush block & 1962 & 1950 & 1940 & 1921 & 1921 & 1921 & 1921 & 1921 & 1921 \\
\hline 7. Fergana block & 1955 & 1920 & 1920 & 1900 & 1880 & 1880 & 1880 & 1880 & 1880 \\
\hline 8. Tien Shan & 1955 & 1930 & 1920 & 1890 & 1890 & 1870 & 1870 & 1870 & 1870 \\
\hline 9. Tarim Basin & 1970 & 1970 & 1970 & 1970 & 1945 & 1930 & 1930 & 1930 & 1930 \\
\hline 10. Eastern Kazakh block & 1958 & 1956 & 1956 & 1886 & 1866 & 1866 & 1866 & 1866 & 1866 \\
\hline
\end{tabular}

Table 1. Completeness analyses for the declustered catalog above magnitude 4.0 for the super zones indicated in Figure 10. 
in both magnitude and epicentral location. An uncertainty of 0.5 and 0.2 for magnitude is used for earthquakes that occurred prior to or later than 1960 , respectively, which corresponds to about the completeness time of magnitude 4 (see Table 1). Regarding the uncertainty in epicentral location, the values indicated in the catalog are used, when available. The uncertainty in epicentral location is not available for some events after 1991, and hence an uncertainty of $5 \mathrm{~km}$ was used.

\subsection{Area seismic sources and recurrence parameters}

The area sources for the study region are defined by mainly considering the pattern of crustal seismicity (here meaning down to $50 \mathrm{~km}$ depth), although tectonic and geological information, such as the position and strike distribution of known faults, have also been taken into account when available. The boundaries of the area sources along with the declustered seismicity distribution are shown in Figure 10. Large area sources (see, for example, those indicated with numbers 1, 2, 5, 45 and 52 in Figure 10) are defined where the seismicity is scarce and there are no tectonic or geological features that would justify a further subdivision. Smaller area sources (e.g., numbers 36 and 53 in Figure 10, around the Talas-Fergana fault) have been designed where the seismicity can be assigned to known fault zones. Amongst these, it is worth mentioning the sources numbered 9, 57, and 58 (Figure 10), including the seismicity generated mainly by the Darvaz and Gissal Kokshal faults (Figure 2). These area sources in- clude the largest number of earthquakes (457 events), the largest one with magnitude of 7.4. The area source 17, which includes the western Tarim basin and southern Tien Shan, is dominated by the seismicity of the Atushi-Keping fault. It is the second area source in terms of number of earthquakes with the largest event of magnitude 6.7. Area source 13 covers the Tajik depression zone ( 234 events, 6.7 being the magnitude of the largest event). Of particular interest are the area sources 46 and 47,covering the Kopet-Dagh range (Turkmen-Khorasan Mountain Range), where the largest number of events greater than magnitude 7(15) occurred, including the 1948 M 7.3 Ashgabat earthquake, which occurred in area source 47 .

The area source number 15 , covering the northern Tien Shan, includes the largest known events that have affected the Central Asia region, namely the 1889 M 8.3 Chilik earthquake, which is one of the largest historic intra-plate reverse faulting events, and the intra-continental 1911 M 8.2, Chon-Kemin earthquake.

Finally, area source 43 , covering part of the territory of Uzbekistan (Turan block) also includes the Gazli gas field. This area source has a peculiar concentration of seismicity within short time periods, with earthquakes larger than magnitude 7 . In particular, three events with $M>=7.0$ have occurred over an eight year time interval (1976-1984). These three events, which occurred in an intra-plate region, where relatively low seismic activity was known before, are considered to be possibly induced by gas extraction [Simpson and Leith 1985].

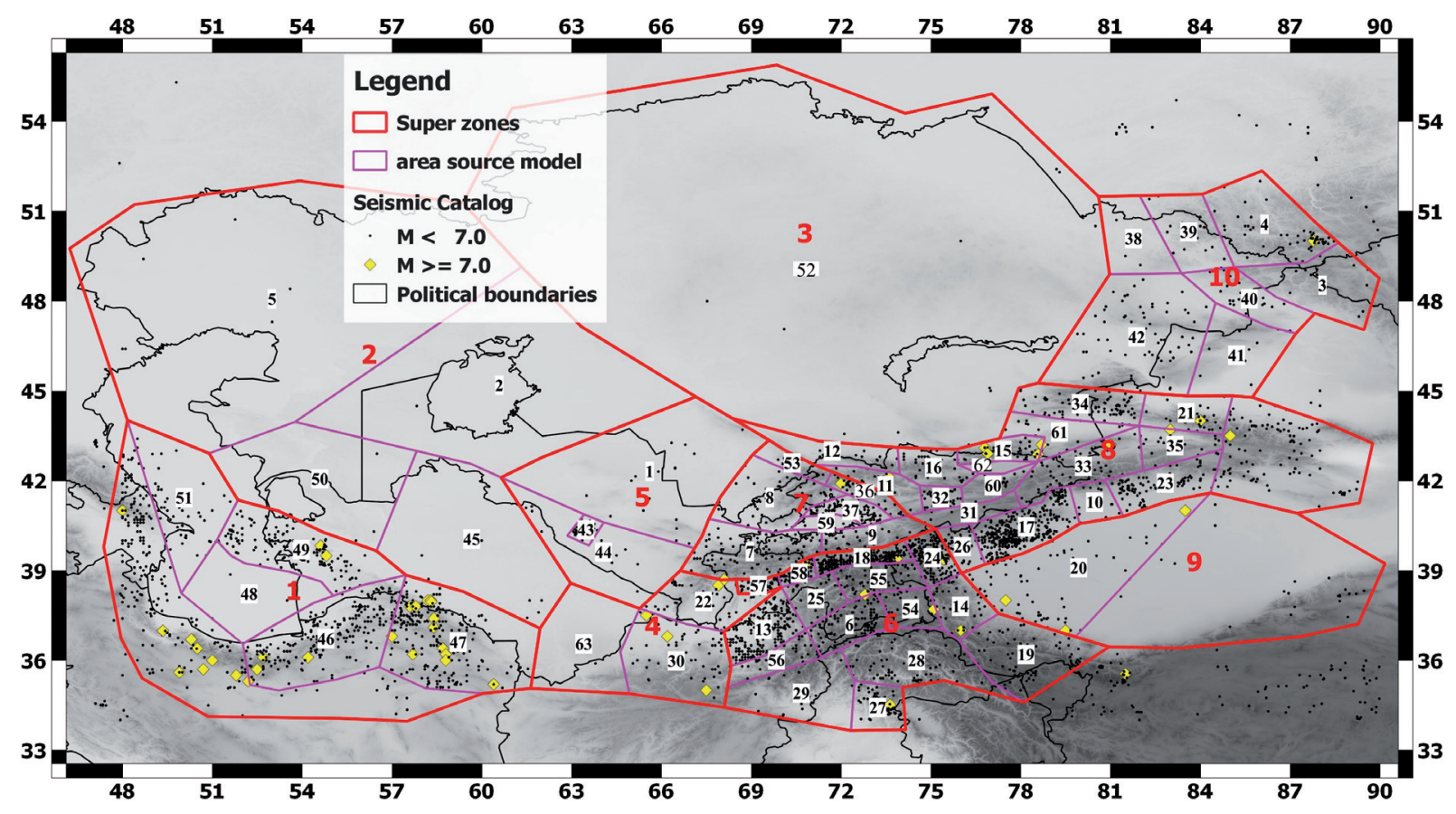

Figure 10. Seismic sources for the study area. The red polygons represent the super zones, the magenta color represent the area sources. The numbers represent the numbering of respective super zones and area sources. The black dots represent the declustered earthquake catalog $\mathrm{MLH}<7.0$, whereas the yellow diamond shapes represent events $\mathrm{MLH}>=7.0$. 
In order to obtain a robust estimation of the necessary parameters for PSHA derived by the statistical analysis of the seismicity, due to the scarcity of data in some of the areas covered by the model, super zones had to be introduced. These super zones are defined by combining area sources based on similarities in their tectonic regime, and taking into account local expert's judgments. Figure 10 shows the super zones that have been used to estimate: (1) the completeness time of the earthquake catalog, (2) the depth distribution of seismicity, (3) the tectonic regime through focal mechanisms analysis, (4) the maximum magnitude and (5) the $b$ values via the GR relationship (Equation 6 ).

It is necessary to estimate the completeness of different magnitudes for the recurrence rates. The magnitude of completeness $(\mathrm{Mc})$ is defined as the lowest magnitude at which $100 \%$ of the earthquakes in a space-time volume are detected. The completeness of the earthquake catalog is a function of magnitude and space (epicenter). The larger the magnitude of an event, the larger is its probability to be detected. Similarly, the detection probability of events also depends on the coverage of the seismic network. In this study, the method of Stepp [1973] is used to estimate the timecompleteness of different magnitude bins in the super zones, considering the declustered catalog. Stepp's method is an analytical approach which is based on estimators of the mean rate of recurrence of earthquakes within given magnitude and time ranges. The completeness magnitude is identified when the observed rates of earthquakes above Mc start to deviate from the expected rate. For completeness analyses, the catalog is divided into 0.5 magnitude interval starting from magnitude 4.0. The analyses are carried out with a time interval of 5 years, using the Hazard Modelers' Toolkit provided by the GEM (Global Earthquake Model) foundation. Figure 11 shows the results of the completeness analysis for the regional catalog. From Figure 11, according to the Stepp method, the regional catalog is completed from about 1956 above magnitude 4 . This is when the monitoring network in Central Asia was upgraded. Due to frequent moderate to strong events, events above magnitude 6 are complete from 1890 . Table 1 summarizes the results of the completeness analysis for the super zones defined in Figure 10. The magnitude represents the central part of the bins. Superzones 2 and 3, which are stable continental regions, do not contain enough events for statistical analysis, and hence these super-zones are assigned the completeness of the regional catalog.

The time-completeness intervals for the different magnitude bins are used to estimate the recurrence relation [Gutenberg and Richter 1944] for the declustered

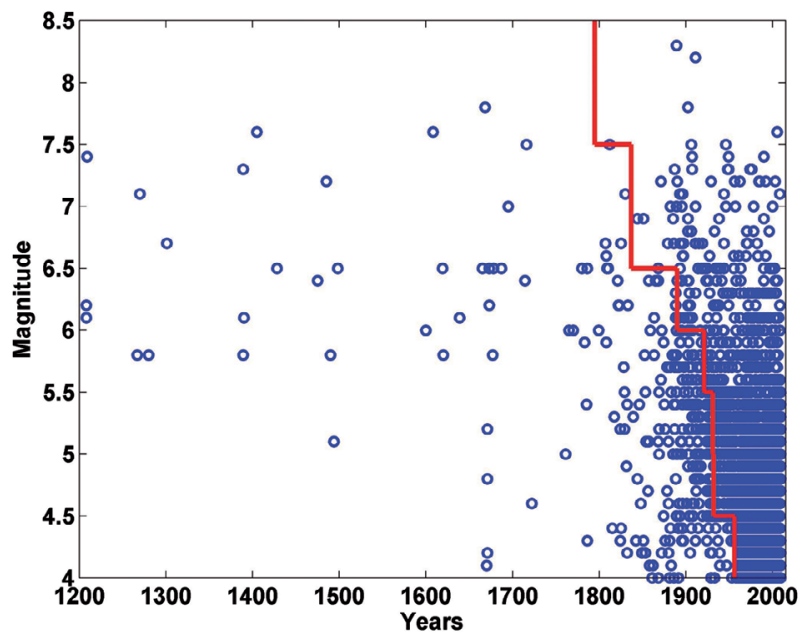

Figure 11. Completeness analysis for the whole declustered catalog using Stepp's Method [Stepp 1973].

catalog. In this study, the Weichert [1980] method is used to estimate the $b$ value (Equation 6 ) for the super zones. This method estimates the maximum likelihood of $b$ values for grouped magnitudes bins and allows for unequal periods of observation. Since super zones 2 and 3 belong to the stable Kazakh block, they do not have enough seismicity to determine this parameter. Hence, in this case, the b-values for these two zones are assumed to be equal to 1 (which is the average $b$ value considered worldwide). Figure 12 shows the recurrence relationship for the regional catalog, along with the observations. The relationship shows a good fit for smaller to moderate magnitude events, but it overestimates the frequency of magnitudes larger than 7 .

The maximum magnitude for each super zone is assigned based on expert's opinion, considering also its historical seismicity. For areal sources, the maximum magnitude is usually taken from the historical seismicity, but due to some uncertainties in the magnitudes of the largest events, opinions of the local experts are also

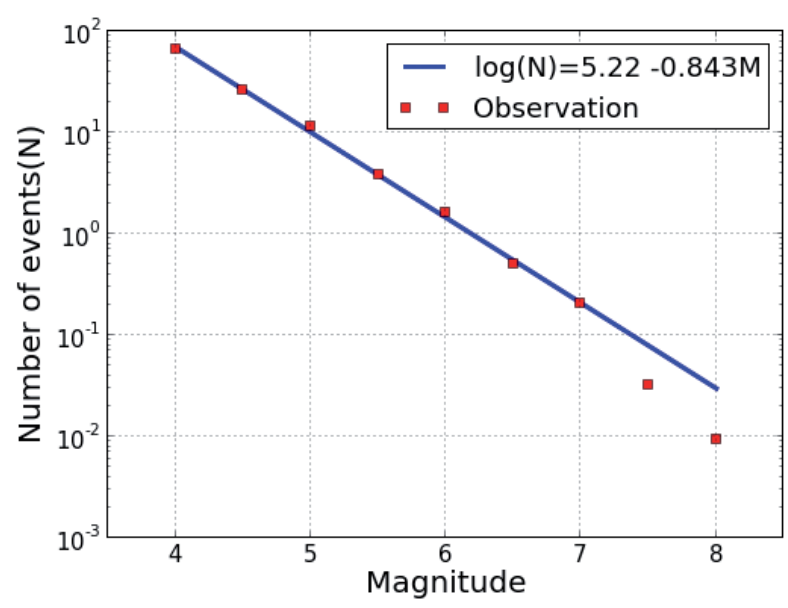

Figure 12. Magnitude-frequency relationship for the whole declustered catalog based on the Weichert method, considering the regional completeness for different magnitude bins. 


\begin{tabular}{|c|c|c|c|c|c|c|c|c|c|c|c|c|c|c|c|}
\hline \multirow{2}{*}{ S.no. } & \multirow{2}{*}{ Name } & \multirow{2}{*}{$\mathbf{b}$} & \multirow{2}{*}{$\operatorname{Mmax}$} & \multicolumn{6}{|c|}{ Hypocentral depth distribution } & \multicolumn{6}{|c|}{ Focal mechanism distribution } \\
\hline & & & & $\mathrm{D}^{\star}{ }^{\star}$ & $W 1^{\star}$ & D2 & W2 & D3 & W3 & $\mathrm{RA1}^{\star}$ & $W 1^{\star}$ & RA2 & W2 & RA3 & W3 \\
\hline 1 & Iranian & 0.88 & 7.3 & & & & & & & & & & & & \\
\hline 1 & block & & & 10 & 0.5 & 35 & 0.25 & 50 & 0.25 & 10 & 0.4 & -100 & 0.2 & 100 & 0.4 \\
\hline 2 & $\begin{array}{c}\text { Kazakh } \\
\text { block }\end{array}$ & 1 & 6 & 15 & 1 & -- & -- & -- & -- & 70 & 1 & -- & -- & -- & -- \\
\hline 3 & $\begin{array}{c}\text { Kazakh } \\
\text { block }\end{array}$ & 1 & 6 & 15 & 1 & -- & -- & -- & -- & 160 & 0.5 & 120 & 0.5 & -- & -- \\
\hline 4 & $\begin{array}{c}\text { Tajik- } \\
\text { Afghan } \\
\text { block }\end{array}$ & 0.6 & 7.3 & 8 & 0.3 & 20 & 0.4 & 35 & 0.3 & 160 & 0.5 & 60 & 0.5 & -- & -- \\
\hline 5 & $\begin{array}{l}\text { Turan } \\
\text { block }\end{array}$ & 1.06 & 7.3 & 15 & 1 & -- & -- & -- & -- & 152 & 0.1 & 100 & 0.9 & -- & -- \\
\hline 6 & $\begin{array}{c}\text { Pamir- } \\
\text { Hindukush } \\
- \\
\text { Karakoram }\end{array}$ & 0.88 & 7.3 & 6 & 0.5 & 35 & 0.5 & -- & -- & 10 & 0.4 & -100 & 0.1 & 100 & 0.5 \\
\hline 7 & $\begin{array}{c}\text { Fergana } \\
\text { block }\end{array}$ & 0.83 & 7.5 & 15 & 0.7 & 35 & 0.3 & -- & -- & 10 & 0.1 & 100 & 0.9 & & \\
\hline 8 & Tien Shan & 0.84 & 8.3 & 15 & 0.4 & 35 & 0.6 & -- & -- & 10 & 0.2 & -80 & 0.1 & 100 & 0.7 \\
\hline 9 & $\begin{array}{l}\text { Tarim } \\
\text { Basin }\end{array}$ & 0.70 & 6.5 & 33 & 1 & -- & -- & -- & -- & 10 & 0.5 & 100 & 0.5 & -- & -- \\
\hline 10 & $\begin{array}{c}\text { Eastern } \\
\text { Kazakh } \\
\text { block }\end{array}$ & 0.72 & 6.5 & 15 & 1 & -- & -- & -- & -- & 10 & 0.5 & 100 & 0.5 & -- & -- \\
\hline
\end{tabular}

Table 2. Characteristics of the super-zones. $\mathrm{D} 1^{\star}=$ hypocentral depth, $\mathrm{RA}{ }^{\star}=$ rake angle, $\mathrm{W} 1^{\star}=$ weight.

included in assigning the maximum magnitude to each super zone. The results of recurrence analysis for the super zones along with the maximum magnitudes are summarized in Table 2 . For example, a maximum magnitude of 8.3 is assigned to the Tien Shan super zone. This zone shows a history of greater seismicity, including the Chillik and Kemin earthquakes. Super zones 2 and 3 are each assigned a maximum magnitude of 6 .

For processing the GR parameters ( $a$ and $b$ values) for the area sources, the completeness analysis results estimated for the super zones are assigned to the respective smaller area sources. If the individual area source has at least 20 events, the GR parameters are then estimated for the area source. Otherwise, the $b$ value is adopted from the respective super zone to which the smaller area source belongs, and the $a$ value is estimated based on the Weichert [1980] method. This ensures the stability in the $b$ value as well as the variation of activity rate for different sources. Figure 13 shows the seismicity within each area source. The light color shows the sources with low seismicity, i.e., below 20 events. The numbers inside each area source shows the number of events for that source. A total of 21 source areas have less than 20 events.

For hazard calculations, each area source is as- signed the maximum magnitude of their respective super zone. The different parameters for the area sources are summarized in Table 3. Since the IPE is considering the hypocentral depths of the events, in Table 3 the hypocentral depth distribution is estimated from the seismicity inside each super zone, using up to three values with corresponding weights.

Maximum magnitude uncertainty is considered by using a weighting scheme for the three values i.e. Mmax +0.5 , Mmax and Mmax -0.5 of 0.2, 0.6 and 0.2, respectively.

The earthquake catalog for focal mechanism is extracted from the Harvard Global Centroid Moment Tensor Catalog [Ekström and Nettles 2013]. For the focal mechanism classification, the Boore et al. [1997] convention is used. This means that an event is considered as strike-slip if the absolute value of the rake angle is $<=30$ or $>=150$ degrees, normal if the rake angle is $<-30$ or $>-150$ and reverse if the rake angle is $>30$ or $<150$ degrees. Figure 14 shows the focal mechanism distribution for the study area, where blue represents reverse faulting, green strike-slip and red normal faulting. As can be seen, the study area is dominated by reverse faulting. There are some occasional normal events in the Pamir and Hindu Kush regions, as well as along 


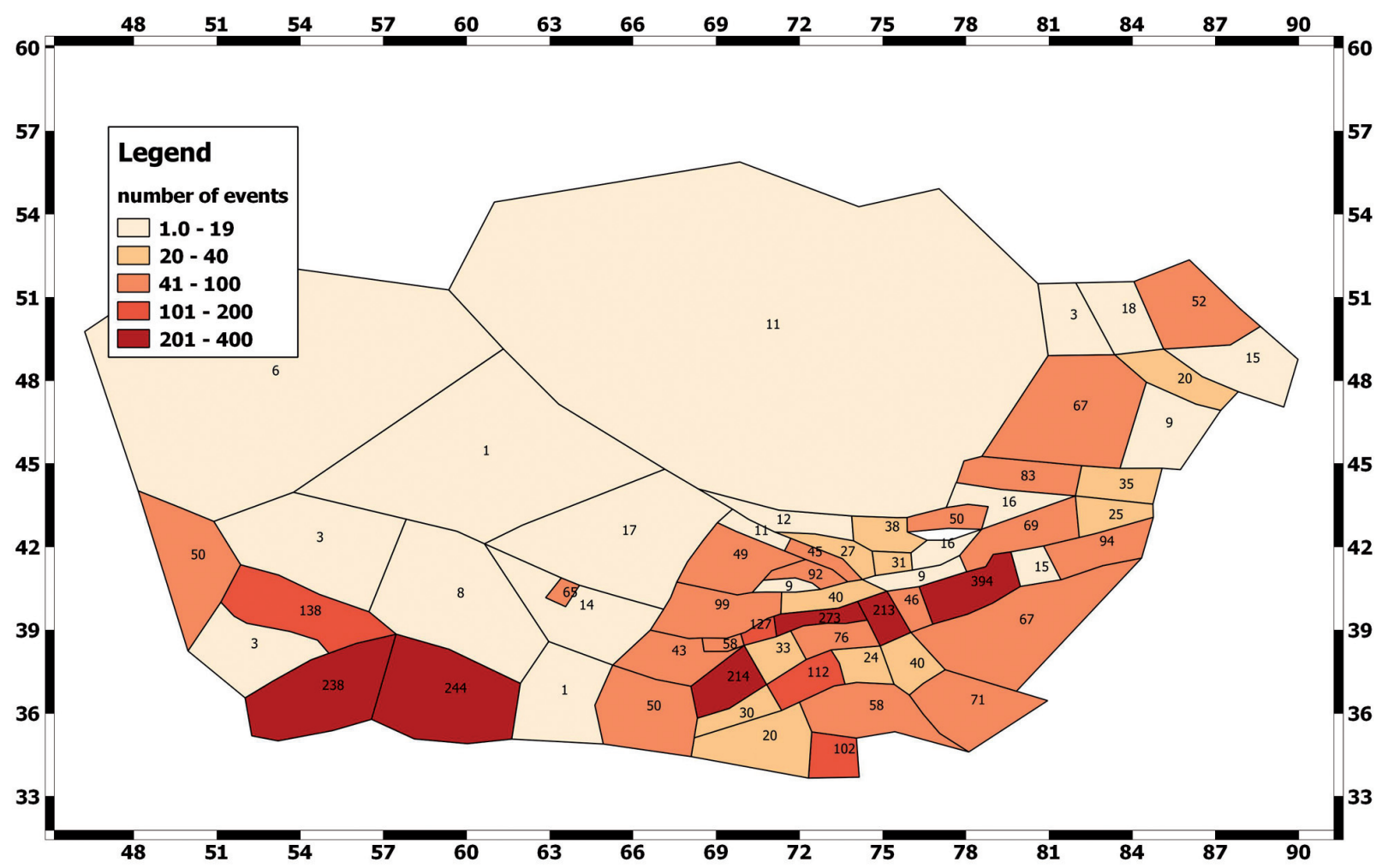

Figure 13. Seismicity inside each area source. The numbers in each area source represent the number of events.

the Caspian Sea in super zone 1. However, strike-slip events are found to be scattered throughout the region. Although the considered IPE for this study does not utilize information about the source mechanism, the distribution of source mechanism and their weight are estimated for the super zones. These distributions, along with the weights, are shown in Table 2.

\section{PSHA results}

The results of smooth seismicity and area source approaches are summarized below.

\subsection{Smooth seismicity results}

The results from smooth seismicity approaches are:

\subsubsection{Results from Frankel approach}

Figure 15 shows the incremental activity rates calculated using the Frankel [1995] approach for fixed and adaptive kernel bandwidths with global (uniform) and gridded $b$ values. Gridded $b$ values are considered from the super zones of the area source model. Areas characterized by high seismicity show high activity rates, such as the Alai valley (running east-west across most of south-west Kyrgyzstan), the Fergana valley across the eastern part of Uzbekistan, Kyrgyzstan and Tajikistan, the boundary between the north-west Tarim basin in north-west China and the southern Tien Shan, and the Kopet-Dagh range (Turkmen-Khorasan Mountain Range) on the border between Turkmenistan and Iran. Clear differences occur between a fixed and an adaptive bandwidth for uniform $b$ values (Figure 15ab), especially in low and high seismicity areas. Since for a fixed bandwidth the same level of smoothing is applied everywhere, the seismicity is further smeared from the areas with a high rate of seismicity. On the other hand, using an adaptive bandwidth, the level of smoothing depends on the seismicity, i.e., in this case, the level of smoothing is lower in areas with a high level of seismicity (e.g., the Alai valley), whereas there is stronger smoothing in areas of low seismicity (e.g., the TajikAfghan block, Uzbekistan). Similar observations can be made in the case of gridded b-values (Figure 15cd). As can be seen, the activity rates are largely influenced by the b-value (e.g., the Gazli field in central Uzbekistan as well as for western Tajikistan).

In Figure 16, the probabilistic seismic hazard for Central Asia in terms of macro-seismic intensities for $10 \%$ probability of exceedance in 50 years based on the approach of Frankel [1995] is given. Using uniform bvalue for fixed and adaptive bandwidth, the highest level of hazard is observed in the Alai valley, Fergana valley and in the Gazli gas field area, reaching an intensity level of up to 7-8 (Figure 16ab). On the other hand, using gridded $b$ values (Figure $16 \mathrm{~cd}$ ), the level of hazard is highest in the Tajik-Uzbekistan border region, reaching a level of 8-9. This high level of hazard is due to the presence of a few large magnitude events (e.g., the 1907 $\mathrm{M}=7.4$ Qaratog earthquake), thus emphasizing low $b$ values. For an adaptive bandwidth, the level of hazard is smoother in the aforementioned areas and less spread 
ULLAH ET AL.

\begin{tabular}{|c|c|c|c|c|c|c|c|c|c|c|c|}
\hline \multirow{2}{*}{$\begin{array}{c}\text { Source } \\
\text { no. }\end{array}$} & \multirow{2}{*}{$\begin{array}{c}\text { Super } \\
\text { zone }\end{array}$} & \multirow{2}{*}{ Mmin } & \multirow{2}{*}{$\operatorname{Mmax}$} & \multirow{2}{*}{ a } & \multirow{2}{*}{$\mathbf{b}$} & \multicolumn{6}{|c|}{ Hypocentral depth distribution } \\
\hline & & & & & & $\mathrm{D} 1^{\star}$ & $\mathrm{W} 1^{\star}$ & $\mathrm{D2}^{\star}$ & $\mathrm{W}^{\star}{ }^{\star}$ & $\mathrm{D3}^{\star}$ & $\mathrm{W}^{\star}{ }^{\star}$ \\
\hline 1 & 5 & 4 & 7.3 & 3.4 & 1.06 & 15 & 1 & -- & -- & -- & -- \\
\hline 2 & 2 & 4 & 6 & 2.3 & 1.00 & 15 & 1 & -- & -- & -- & -- \\
\hline 3 & 10 & 4 & 6.5 & 2.3 & 0.72 & 15 & 1 & -- & -- & -- & -- \\
\hline 4 & 10 & 4 & 6.5 & 2.8 & 0.74 & 15 & 1 & -- & -- & -- & -- \\
\hline 5 & 2 & 4 & 6 & 2.9 & 1.00 & 15 & 1 & -- & -- & -- & -- \\
\hline 6 & 6 & 4 & 7.3 & 3.9 & 0.87 & 6 & 0.5 & 35 & 0.5 & -- & -- \\
\hline 7 & 7 & 4 & 7.5 & 3.1 & 0.76 & 15 & 1 & -- & -- & -- & -- \\
\hline 8 & 7 & 4 & 7.5 & 2.6 & 0.70 & 15 & 1 & -- & -- & -- & -- \\
\hline 9 & 7 & 4 & 7.5 & 3.4 & 0.89 & 15 & 0.4 & 35 & 0.6 & -- & -- \\
\hline 10 & 8 & 4 & 8.3 & 2.8 & 0.84 & 33 & 1 & -- & -- & -- & -- \\
\hline 11 & 8 & 4 & 8.3 & 2.3 & 0.68 & 15 & 0.4 & 35 & 0.6 & -- & -- \\
\hline 12 & 8 & 4 & 8.3 & 2.5 & 0.84 & 15 & 1 & -- & -- & -- & -- \\
\hline 13 & 6 & 4 & 7.3 & 4.7 & 0.98 & 6 & 0.5 & 35 & 0.5 & -- & -- \\
\hline 14 & 6 & 4 & 7.3 & 3.1 & 0.81 & 8 & 0.3 & 20 & 0.4 & 35 & 0.3 \\
\hline 15 & 8 & 4 & 8.3 & 1.7 & 0.50 & 15 & 1 & -- & -- & -- & -- \\
\hline 16 & 8 & 4 & 8.3 & 2.4 & 0.70 & 15 & 1 & -- & -- & -- & -- \\
\hline 17 & 8 & 4 & 8.3 & 4.3 & 0.87 & 15 & 0.4 & 35 & 0.6 & -- & -- \\
\hline 18 & 6 & 4 & 7.3 & 3.9 & 0.80 & 6 & 0.7 & 35 & 0.3 & -- & -- \\
\hline 19 & 6 & 4 & 7.3 & 3.1 & 0.72 & 8 & 0.3 & 20 & 0.4 & 35 & 0.3 \\
\hline 20 & 9 & 4 & 6.5 & 2.9 & 0.71 & 8 & 0.3 & 20 & 0.4 & 35 & 0.3 \\
\hline 21 & 8 & 4 & 8.3 & 2.2 & 0.60 & 15 & 0.4 & 35 & 0.6 & -- & -- \\
\hline 22 & 4 & 4 & 7.3 & 2.2 & 0.61 & 15 & 1 & -- & -- & -- & -- \\
\hline 23 & 8 & 4 & 8.3 & 3.6 & 0.83 & 33 & 1 & -- & -- & -- & -- \\
\hline 24 & 6 & 4 & 7.3 & 3.6 & 0.77 & 6 & 0.7 & 35 & 0.3 & -- & -- \\
\hline 25 & 6 & 4 & 7.3 & 3.3 & 0.85 & 8 & 0.3 & 20 & 0.4 & 35 & 0.3 \\
\hline 26 & 8 & 4 & 8.3 & 2.2 & 0.60 & 6 & 0.7 & 35 & 0.3 & -- & -- \\
\hline 27 & 6 & 4 & 7.3 & 3.0 & 0.68 & 6 & 0.5 & 35 & 0.5 & -- & -- \\
\hline 28 & 6 & 4 & 7.3 & 3.0 & 0.72 & 8 & 0.3 & 20 & 0.4 & 35 & 0.3 \\
\hline 29 & 6 & 4 & 7.3 & 3.1 & 0.84 & 6 & 0.5 & 35 & 0.5 & -- & -- \\
\hline 30 & 4 & 4 & 7.3 & 2.3 & 0.60 & 15 & 1 & -- & -- & -- & -- \\
\hline 31 & 8 & 4 & 8.3 & 2.5 & 0.84 & 15 & 0.4 & 35 & 0.6 & -- & -- \\
\hline 32 & 8 & 4 & 8.3 & 2.1 & 1.00 & 15 & 0.4 & 35 & 0.6 & -- & -- \\
\hline 33 & 8 & 4 & 8.3 & 3.4 & 0.80 & 15 & 0.4 & 35 & 0.6 & -- & -- \\
\hline 34 & 8 & 4 & 8.3 & 3.4 & 0.82 & 15 & 0.4 & 35 & 0.6 & -- & -- \\
\hline 35 & 8 & 4 & 8.3 & 2.0 & 0.70 & 15 & 0.4 & 35 & 0.6 & -- & -- \\
\hline 36 & 7 & 4 & 7.5 & 3.6 & 0.95 & 6 & 0.7 & 35 & 0.3 & -- & -- \\
\hline 37 & 7 & 4 & 7.5 & 3.0 & 0.73 & 6 & 0.7 & 35 & 0.3 & -- & -- \\
\hline 38 & 10 & 4 & 6.5 & 1.2 & 0.72 & 15 & 1 & -- & -- & -- & -- \\
\hline 39 & 10 & 4 & 6.5 & 2.0 & 0.72 & 15 & 1 & -- & -- & -- & -- \\
\hline 40 & 10 & 4 & 6.5 & 2.5 & 0.72 & 15 & 1 & -- & -- & -- & -- \\
\hline 41 & 10 & 4 & 6.5 & 2.1 & 0.72 & 15 & 0.4 & 35 & 0.6 & -- & -- \\
\hline 42 & 10 & 4 & 6.5 & 4.1 & 1.03 & 15 & 0.4 & 35 & 0.6 & -- & -- \\
\hline 43 & 5 & 4 & 7.3 & 3.9 & 0.92 & 15 & 1 & -- & -- & -- & -- \\
\hline
\end{tabular}

Table 3 (continues on next page). Area source parameters. $\mathrm{D} 1^{\star}=$ hyopcentral depth, $\mathrm{W} 1^{\star}=$ weight. 


\begin{tabular}{|c|c|c|c|c|c|c|c|c|c|c|c|}
\hline \multirow{2}{*}{$\begin{array}{c}\text { Source } \\
\text { no. }\end{array}$} & \multirow{2}{*}{$\begin{array}{l}\text { Super } \\
\text { zone }\end{array}$} & \multirow{2}{*}{ Mmin } & \multirow{2}{*}{ Mmax } & \multirow{2}{*}{ a } & \multirow{2}{*}{$\mathbf{b}$} & \multicolumn{6}{|c|}{ Hypocentral depth distribution } \\
\hline & & & & & & $\mathrm{D} 1^{\star}$ & $\mathrm{W} 1^{\star}$ & $\mathrm{D}^{\star \star}$ & $\mathrm{W}^{\star}{ }^{\star}$ & $\mathrm{D3}^{\star}{ }^{\star}$ & $\mathrm{W}^{\star}{ }^{\star}$ \\
\hline 44 & 5 & 4 & 7.3 & 3.5 & 1.06 & 15 & 1 & -- & -- & -- & -- \\
\hline 45 & 2 & 4 & 6 & 3.1 & 1.00 & 15 & 1 & -- & -- & -- & -- \\
\hline 46 & 1 & 4 & 7.3 & 4.1 & 0.89 & 10 & 0.5 & 35 & 0.25 & 50 & 0.25 \\
\hline 47 & 1 & 4 & 7.3 & 3.4 & 0.72 & 10 & 0.5 & 35 & 0.25 & 50 & 0.25 \\
\hline 48 & 1 & 4 & 7.3 & 1.8 & 0.88 & 10 & 0.5 & 35 & 0.25 & 50 & 0.25 \\
\hline 49 & 1 & 4 & 7.3 & 3.8 & 0.88 & 10 & 0.5 & 35 & 0.25 & 50 & 0.25 \\
\hline 50 & 2 & 4 & 6 & 2.3 & 1.00 & 15 & 1 & -- & -- & -- & -- \\
\hline 51 & 1 & 4 & 7.3 & 3.1 & 0.79 & 15 & 1 & -- & -- & -- & -- \\
\hline 52 & 3 & 4 & 6 & 3.0 & 1.00 & 15 & 1 & -- & -- & -- & -- \\
\hline 53 & 7 & 4 & 7.5 & 2.0 & 0.72 & 15 & 1 & -- & -- & -- & -- \\
\hline 54 & 6 & 4 & 7.3 & 3.3 & 0.90 & 8 & 0.3 & 20 & 0.4 & 35 & 0.3 \\
\hline 55 & 6 & 4 & 7.3 & 3.5 & 0.84 & 8 & 0.3 & 20 & 0.4 & 35 & 0.3 \\
\hline 56 & 6 & 4 & 7.3 & 3.2 & 0.79 & 6 & 0.5 & 35 & 0.5 & -- & -- \\
\hline 57 & 6 & 4 & 7.3 & 4.3 & 1.00 & 8 & 0.3 & 20 & 0.4 & 35 & 0.3 \\
\hline 58 & 6 & 4 & 7.3 & 3.0 & 0.77 & 8 & 0.3 & 20 & 0.4 & 35 & 0.3 \\
\hline 59 & 7 & 4 & 7.5 & 2.0 & 0.72 & 6 & 0.7 & 35 & 0.3 & -- & -- \\
\hline 60 & 8 & 4 & 8.3 & 3.0 & 0.83 & 15 & 0.4 & 35 & 0.6 & -- & -- \\
\hline 61 & 8 & 4 & 8.3 & 3.0 & 0.83 & 15 & 0.4 & 35 & 0.6 & -- & -- \\
\hline 62 & 8 & 4 & 8.3 & 1.0 & 0.83 & 15 & 0.4 & 35 & 0.6 & -- & -- \\
\hline 63 & 4 & 4 & 7.3 & 1.0 & 0.60 & 15 & 1 & -- & -- & -- & -- \\
\hline
\end{tabular}

Table 3 (continued from previous page). Area source parameters. D1 ${ }^{\star}=$ hyopcentral depth, $\mathrm{W} 1^{\star}=$ weight.

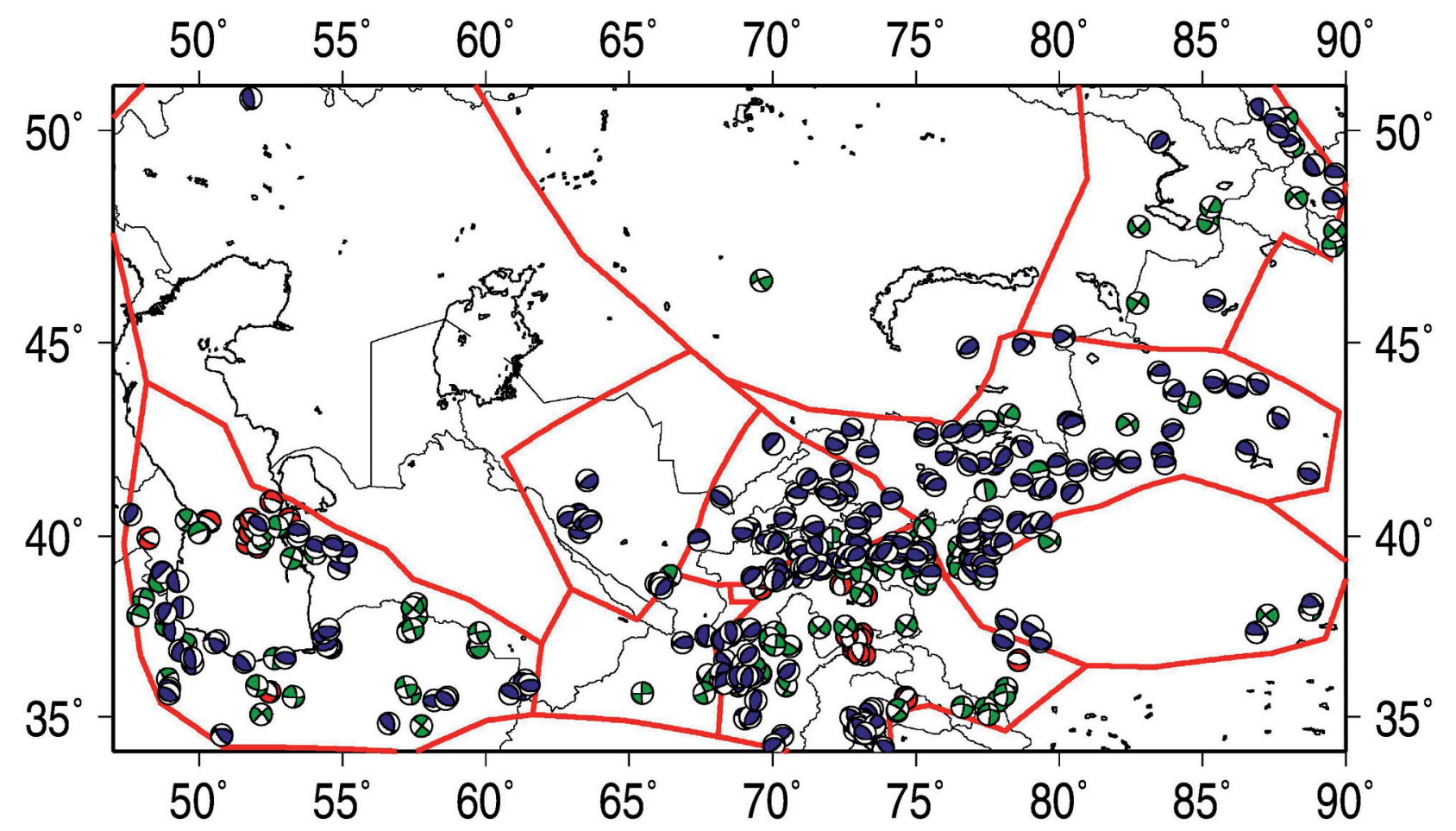

Figure 14. Earthquake focal mechanism map extracted from Harvard Global Centroid Moment Tensor Catalog. The blue, green and red colors represent reverse, strike-slip and normal faulting mechanisms, respectively. 


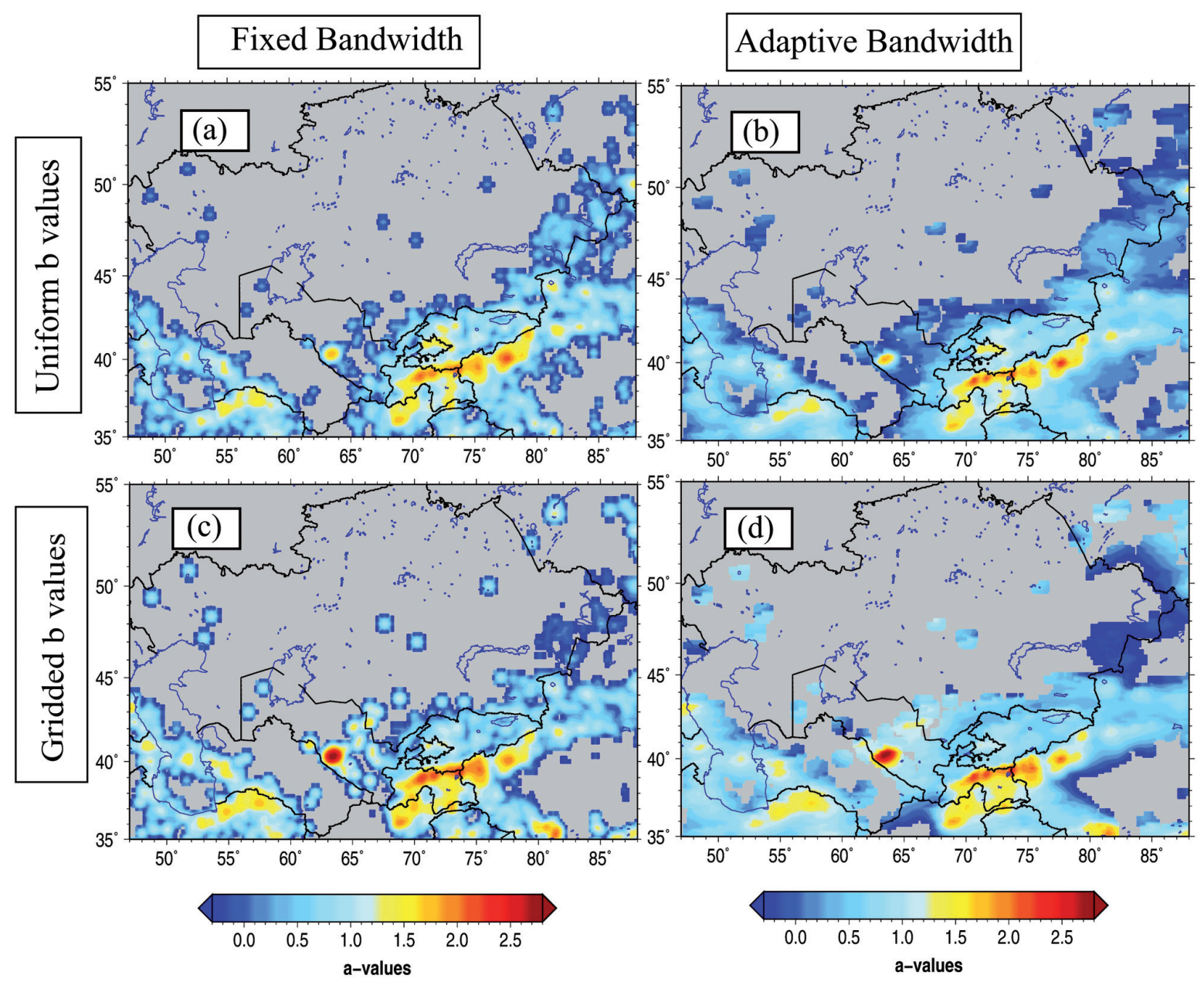

Figure 15. Incremental activity rates calculated using the Frankel approach. (a) Fixed bandwidth, regional $b$ value, (b) adaptive bandwidth, regional $b$ value, (c) fixed bandwidth, gridded $b$ value, and (d) adaptive bandwidth gridded $b$ value.

around the Fergana valley, where very large magnitude events have never been recorded.

\subsubsection{Results from Woo approach}

Using the Woo [1996] approach, Figure 17 shows the level of seismic hazard assessed using magnitudedependent bandwidths for the smoothing procedure. Compared to the results shown in Figure 16, areas of higher hazard levels are much more smeared. This is due to a fixed smoothing distance which depends on the event's magnitude. Thereon, high levels of intensity are assessed for the Issyk-Kul region in eastern Kyrgyzstan, the Tien Shan and Pamir mountain ranges and for large parts around the Gazli gas field in central Uzbekistan, where the highest magnitude events affect the hazard estimates over large distances.

\subsection{Results from area sources}

Figure 18a shows the macroseismic intensity distribution obtained by considering the area source model for a probability of $10 \%$ to be exceeded, i.e., a return period of 475 years. In this case, the influence of considering the seismic sources on the estimated level of hazard can be clearly identified. As expected, areas with a high level of seismicity and with lower b-values show a significantly higher level of hazard (e.g., the Kyrgyz-Kazakh border region north of Issyk-Kul, the Alai valley around the Kyrgyz-Tajik border, the northern part of the Fergana valley). Furthermore, note that for large areas of the stable region of central Kazakhstan, intensity values of around 3 have been derived, fixing a background level corresponding to areas not, or only slightly, affected by seismicity.

Using a $2 \%$ probability of exceedance in 50 years, which corresponds to a return period of 2475 years, the maximum level of hazard reaches intensities up to 9 in the Kyrgyz-Kazakh border region (Figure 18 b). All of Kyrgyzstan and Tajikistan, as well as the eastern parts of Uzbekistan, are characterized by intensity levels higher than 7. For the stable region of central Kazakhstan, a macroseismic intensity of up to 4 is estimated.

\subsection{Hazard curve for selected cities}

To emphasize the level of hazard for the most important cities in Central Asia (Figure 1), Figure $19 \mathrm{com}$ pares the level of hazard for a $10 \%$ and a $2 \%$ probability of exceedance in 50 years, derived using the smoothed seismicity approaches and area source models. In the 

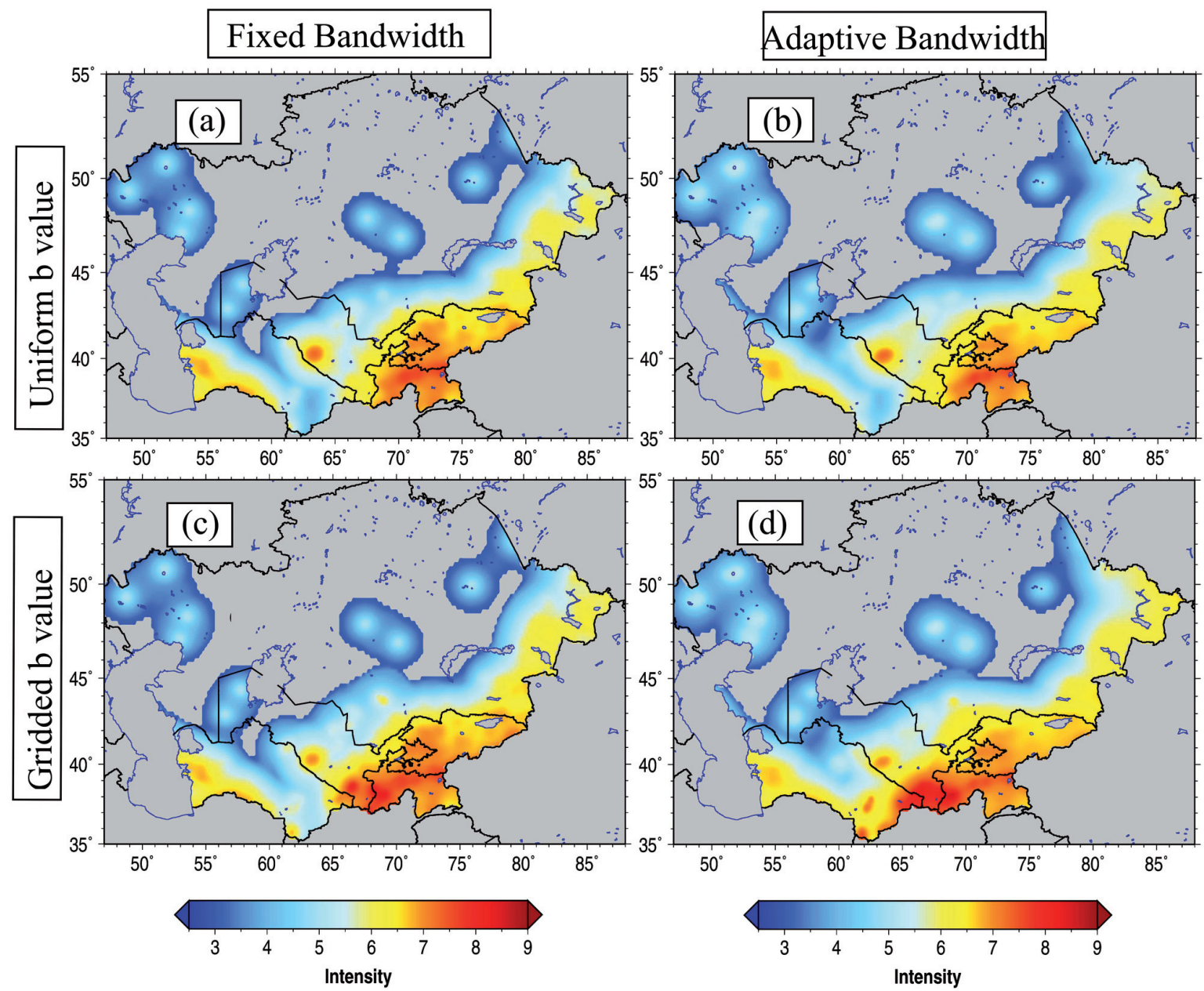

Figure 16. Probabilistic seismic hazard estimated for Central Asia in terms of macro-seismic intensities for $10 \%$ probability of exceedance in 50 years from Frankel [1995] approach. (a) Fixed bandwidth, regional $b$ value (b) adaptive bandwidth, regional $b$ value, (c) fixed bandwidth, gridded $b$ value, and (d) adaptive bandwidth, gridded $b$ value.

case of the Frankel approach, the results are shown for gridded $b$ values and an adaptive kernel.

For the Kyrgyz capital, Bishkek, the Frankel [1995] approach provides the lowest level of hazard with an intensity of 6-7 having $10 \%$ probability of exceedance in 50 years. Although the curves for the area source model and the Woo [1996] approach provide similar hazard values, only for Bishkek does the Woo [1996] approach provide the highest intensity level.

Similar conditions hold for the city of Almaty, for which the method of Frankel [1995] provides the lowest level of hazard, with intensities of around 6 and 7 for return periods of 475 and 2475 years, respectively. However, the three curves are much more spread apart. The highest hazard levels are assessed when considering the area source model, leading to an intensity level of 8 for $10 \%$ probability of exceedance in 50 years.

For Dushanbe, the agreement between the area sources curve and the curve of the Frankel [1995] approach is noticeable. Whereas the area source model shows a high probability of exceedance for low intensity values, the curve decreases more steeply for higher intensity values, approaching the curve calculated by the Woo [1996] approach. For all intensity levels, the Woo [1996] method provides the lowest level of hazard, both for low and high probabilities of exceedance.

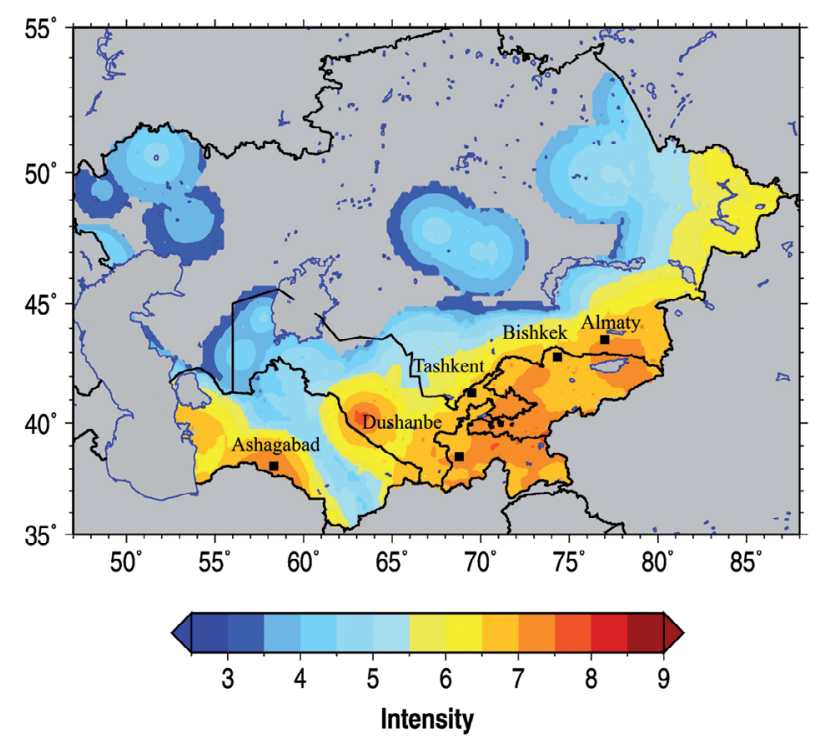

Figure 17. Probabilistic seismic hazard estimated for Central Asia in terms of macro-seismic intensities for $10 \%$ probability of exceedance in 50 years using the Woo [1996] approach. 

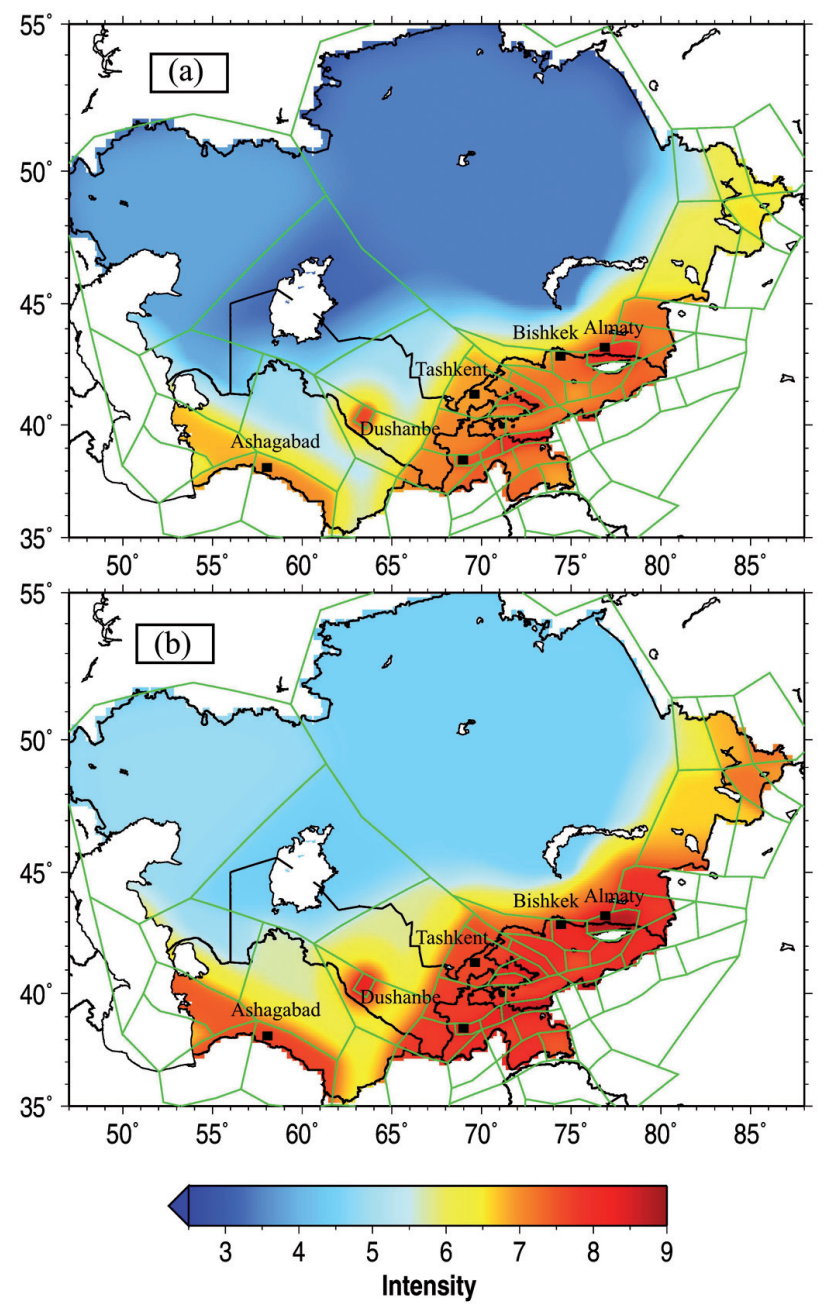

Figure 18. Probabilistic seismic hazard in terms of macro-seismic intensities for a (a) $10 \%$ probability and (b) $2 \%$ probability of exceedance in 50 years using the area source model. The green lines represent the area sources.

For the Uzbek capital Tashkent, all three curves are rather congruent. All in all, the intensity levels are lower here than for the other cities, with values of around 7 for a $10 \%$ probability of exceedance in 50 years and only around $7-8$ for a $2 \%$ probability of exceedance compared to, for example, 8 in Almaty.

\section{Discussion}

In principle, due to the shortness of the earthquake catalog, and the lack of geological and tectonic knowledge, neither of the considered approaches can be considered as providing more realistic results than the other. They are therefore simply different representations of several, but well established approaches, requiring different degrees of expert judgment and/or trust in the completeness of the available information, with their own drawbacks and advantages. However, the presented results confirm that the design and geometry of the seismogenic zones for the area source model (Figure 10) has a major influence on the distribution of the hazard, which is strongly concentrated inside the boundaries of the seismogenic zones (see Figure 18). As reflected by historical seismicity, such a spatial clustering might also be correlated to a marked temporal clustering. Such observations have already been revealed by statistical analyses both at the regional [Faenza et al. 2003] and local scales [Gómez and Pacheco 2004]. In any case, the biases in most cases cannot be easily corrected by simply altering some boundaries, meaning it is clear that a different seismotectonic zonation could be proposed and checked by using different approaches [e.g., Musson 2005]. However, one should be aware that any reduction of the sizes of seismogenic zones also reduces the amount of data available for the statistical parameterization of seismicity in each zone. Consequently, this under sampling may adversely affect the hazard estimate. Whereas Algermissen et al. [1982] suggested a lower limit of 40 events in each zone to avoid this problem, the work by Bender [1983] provided some estimates that, with less than 25 events in each zone, the relative error on b-values could exceed $25 \%$. Therefore, to be on the safe side, for our study we adopted a regional super zone b-value if the number of events is below the threshold of 20 events. As pointed out by Wiemer et al. [2009], this addresses a long-standing need in hazard assessment, and it stabilizes the resulting model by avoiding large fluctuations in $b$ values which is evident, e.g., in super zone 8 (see Figure 10 and Table 3 and the resulting Figure 18).

In zone-free approaches, the predicted areas of high intensities are subject to the $b$ value calculation scheme. The gridded seismicity model emphasizes the expectation that future large, damaging earthquakes are more likely to occur at sites near the epicenters of previous moderate earthquakes, i.e., in areas of large $b$ values corresponding to the southern part of our study area where large magnitude seismicity is located. On the other hand, the use of a uniform $b$ value for fixed and adaptive bandwidths smooth's out this effect and significantly lowers the levels of hazard in these areas. The highest hazard levels can be found in zones subjected to a large number of past earthquakes, as reported in the earthquake catalog (e.g., the Tajik-Kyrgyz border region, south-western Tajikistan), thus revealing a different spatial distribution and pattern of hazard estimates. Almost no influence of the large magnitude events that occurred in the northern part of the study area on the final hazard estimates can be identified.

When comparing the results, the zoning and smoothing approaches can be seen to yield similar hazard estimates for low to moderate seismicity regions. This means that the results are directly related to the seismicity models used, but their comparison can lead to very different scenarios, depending on the site being 

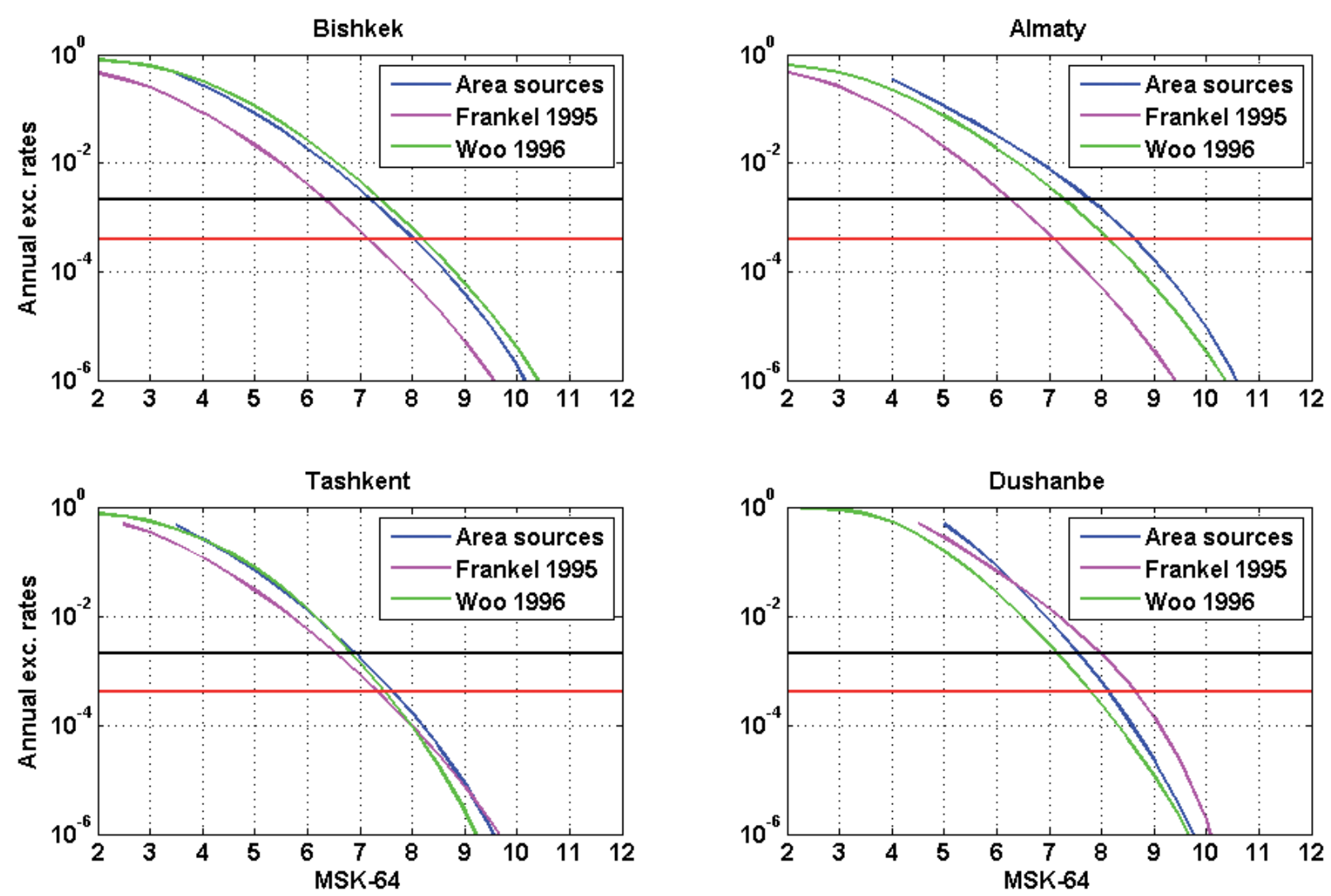

Figure 19. Hazard curves for the major cities of Central Asia using the smoothed seismicity approaches and area source model. In the case of the Frankel [1995] approach, the results are shown for gridded $b$ values and adaptive kernel. The black and red lines correspond to a $10 \%$ and $2 \%$ probability of exceedance in 50 years, respectively.

studied. Such disaggregation results strictly depend on the seismicity distribution, that is, on the proximity to sources where the seismicity is mainly concentrated. Distant, larger magnitude events dominate the hazard in areas characterized by low-seismic activity. Conversely, nearby seismicity is often the major contributor to the hazard at sites located in high-seismicity regions or in zones where the seismic activity is characterized by weak-to-moderate, but quite frequent, events. In line with the findings of Molina et al. [2001] and Beauval et al. [2006], the fixed kernel method might yield compatible results when compared to the classical zonation approach, whereas for high seismicity regions, using a fixed bandwidth yields lower hazard values when compared to those from the zonation method.

This is particularly obvious for the most important cities in Central Asia (Figure 19) for which - with the exception of Dushanbe - the area source model provides a higher level of hazard. Whereas the zoning method requires homogeneous source zones and a frequency-magnitude distribution for each source zone, Woo [1996] proposed to use maps of smoothed epicenter locations, which are smoothed according to the fractal distribution of earthquakes in space [e.g., Kagan and Jackson 2000]. Although originally the method of Woo [1996] did not allow for the occurrence of magnitudes greater than the maximum magnitude observed, we have accounted for earthquakes larger than historical ones by considering an uncertainty of 0.5 in magnitude for the historical events of the catalogue (before 1960) and 0.2 in magnitude for more recent events, increasing the level of hazard.

Although the results of the latest study on the region, GSHAP [Giardini 1999], who published a homogenized seismic hazard map in terms of peak ground acceleration at a $10 \%$ probability of exceedance in 50 years, have been a major step towards a cross-border approach for the entire region, the conducted PSHA, employing a rather homogeneous distribution in terms of PGA for large parts of Central Asia, might be assumed to be outdated for several reasons (Figure 20). This includes the fact that much progress has been made in the development of region-specific ground motion prediction equations [e.g., Bindi et al. 2011], the treatment of uncertainties within a PSHA has been improved, and new model ideas have been developed. Figure 20 shows the seismic hazard calculated in GSHAP project in terms of $10 \%$ probability of exceedance in 50 years, converted from pga to macroseismic intensity using the relationship of Tselentis and Danciu [2008]. Comparing Figure 20 with the current study shows a couple of magnitudes higher seismic hazard from GSHAP project. Also comparing the results from the site approach for the region 


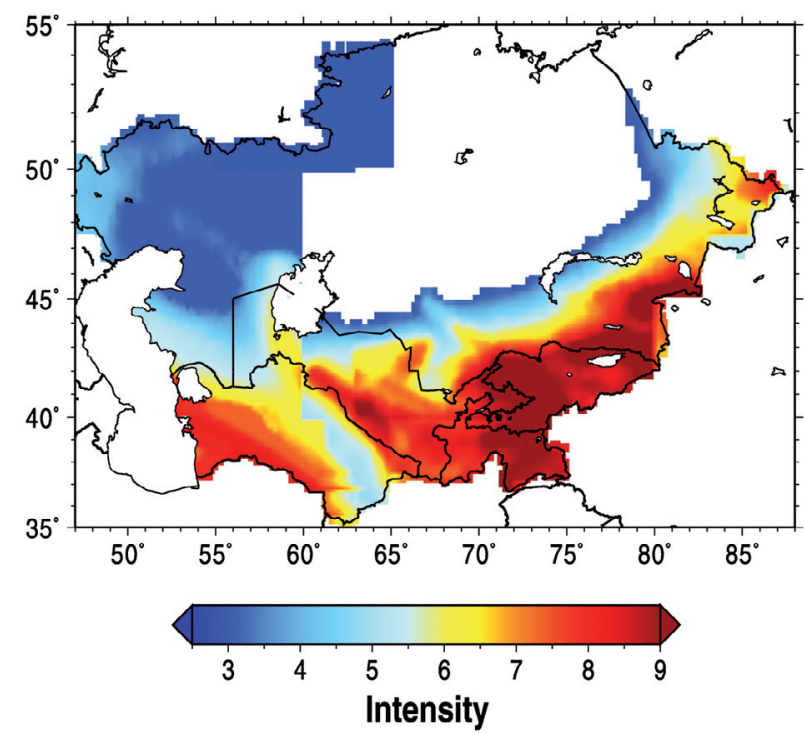

Figure 20. Results of PSHA for Central Asia in terms of macro-seismic intensities for $10 \%$ probability of exceedance in 50 years from GSHAP project. The relationship of Tselentis and Danciu [2008] is used to convert the pga to macroseismic intensity.

[Bindi et al. 2012], shows a higher level of seismic hazard compared to this study. Figure 6 of Bindi et al. [2012] shows seismic hazard of intensities 9, 9, 9 and 10 for Bishkek, Dushanbe, Tashkent and Almaty, respectively for $10 \%$ probability of exceedance in 50 years. While the main activity centers around the Fergana and Alai valleys remain dominant in the hazard assessments, the maps presented here are more diverse across the region. Greater discrimination is found, specifically along the border between Turkmenistan and Uzbekistan, central Kyrgyzstan and eastern Tajikistan. In particular, such large regions as Central Asia are characterized by rather different seismic regimes and regionally varying features and degrees of catalogue completeness, all of which need to be taken into account for a proper seismic hazard assessment on a regional scale.

On the other hand, the results presented for the most important cities, i.e., the results for the local scale, have to be seen as part of a regional large-scale study. For site-specific investigations of engineering interest, local conditions, especially concerning the local geological conditions, the regionalization, and more detailed attenuation relationships, need to be considered (see the paper of Ullah et al. [2015], this issue).

In the end, none of the models can be seen as the final result since differences still arise when based on the same data set. A zone-free approach, which does not include so much in terms of expert judgment, might be seen as the most objective model. However, it is doubtful if the "objectivity" of such techniques that avoid regionalization can compensate for the deliberate omission of distinct geological and seismological knowledge. The weight to be assigned at the results ob- tained with the two methods should be compatible with the quality and extension of historical catalogs, with the observed instrumental seismicity, and with the geological and tectonic information available. Since the final goal is to maximize the reliability of hazard estimates by making the best use of all accessible data, this capability might be best exploited to reduce uncertainty in computing seismic hazard in Central Asia, with their incomplete catalogues and where seismogenic structures are generally not easily detectable.

\section{Conclusion}

We have carried out an updated trans-national probabilistic seismic hazard assessment based on the direct analysis of local seismic histories provided by the smoothed seismicity approach, and the standard Cornell [1968] approach based on source areas. The seismic hazard is estimated in terms of macroseismic intensity (MSK-64), intended to be used for the seismic risk maps of the region. Although the methods reveal clear differences between each other in terms of absolute hazard levels, the locations of the highest levels of hazard are rather congruent. These regions cover the Alai valley, the Fergana valley, and the region north of Issyk-Kul, and are characterized by intensity levels of more than 8 for the area source model. The maximum hazard observed in the region shows an intensity level of 9 in southern Tien Shan for a return period of 475 years. The comparison between the different approaches shows that rank differences are mainly related to the seismotectonic zoning. For the future, to undertake seismic hazard assessments of engineering interest, further studies are needed, including the consideration of zones of diffuse and concentrated seismicity and a comprehensive uncertainty analysis of epistemic and aleatory variables, such as alternative seismic source models, different earthquake catalogues and uncertainty in the estimated recurrence rates and vibratory ground motion values.

Acknowledgements. We are grateful to all the participants involved in EMCA project for their valuable contributions and suggestions. Dr. Kevin Fleming kindly revised our English. Shahid Ullah carried out this work within the Global Earthquake Model (GEM) regional project earthquake Model Central Asia (EMCA) while a doctoral student at the Technical University Berlin. His study at TU Berlin is supported by a developmental project "Strengthening of existing earthquake engineering center" University of Engineering $\&$ Technology, Peshawar Pakistan. We are grateful to Dr. Mariano Garcia-Fernandez for his constructive comments and suggestions to improve the quality of the manuscript.

\section{References}

Abdrakhmatov, K.Y., S.A. Aldazhanov, B.H. Hager, M.W. Hamburger, T.A. Herring, K.B. Kalabaev, V.I. Makarov, P. Molnar, S.V. Panasyuk, M.T. Prilepin, 
R.E. Reilinger, I.S. Sadybakasov, B.J. Souter, Y.A. Trapeznikov, V.Y. Tsurkov and A.V. Zubovich (1996). Relatively recent construction of the Tien Shan inferred from GPS measurements of present-day crustal deformation rates, Nature, 384, 450-453.

Abdrakhmatov, K., H.-B. Havenith, D. Delvaux, D. Jongmans and P. Trefois (2003). Probabilistic PGA and Arias Intensity maps of Kyrgyzstan (Central Asia), J. Seismol., 7, 203-220

Algermissen, S.T., D.M. Perkins, P.C. Thenhaus, S.L. Hanson and B.L. Bender (1982). Probabilistic estimates of maximum acceleration and velocity in rock in the contiguous United States, U.S. Geol. Surv., Open-File Report, 80-1033.

Aptikaev, F.F., and N.V. Shebalin (1988). Specification of correlation between level of macroseismic effect and dynamic parameters of ground movements, researches on seismic danger, Question of Engineering Seismology, 29, 98-107 (in Russian).

Beauval, C., S. Hainzl and F. Scherbaum (2006). Probabilistic seismic hazard estimation in low-seismicity regions considering non-Poissonian seismic occurrence, Geophys. J. Int., 164, 543-550.

Bender, B. (1983). Maximum likelihood estimation of b-values for magnitude grouped data, B. Seismol. Soc. Am., 73, 831-851.

Bindi, D., S. Parolai, A. Oth, K. Abdrakhmatov, A. Muraliev and J. Zschau (2011). Intensity Prediction Equations for Central Asia, Geophys. J. Int., 187 (1), 327-337; doi:10.1111/j.1365-246X.2011.05142.x.

Bindi, D., K. Abdrakhmatov, S. Parolai, M. Mucciarelli, G. Grünthal, A. Ischuk, N. Mikhailova and J. Zschau (2012). Seismic hazard assessment in Central Asia: Outcomes from a site approach, Soil Dyn. Earthq. Eng., 37, 84-91.

Boore, D.M., W.B. Joyner and T.E. Fumal (1997). Equations for estimating horizontal response spectra and peak acceleration from western North American earthquakes: a summary of recent work, Seismol. Res. Lett., 68, 129-153.

Bune, V.I., and G.P. Gorshkov, eds. (1980). Seismic zonation of USSR, Moscow, Nauka, 307 pp. (in Russian).

Burtman, V.S., and P. Molnar (1993). Geological and Geophysical Evidence for Deep Subduction of Continental Crust Beneath the Pamir, Geological Society of America, Boulder, Special Paper 281, 76 pp.

Cornell, C.A. (1968). Engineering seismic risk analysis, B. Seismol. Soc. Am., 58, 1583-1606.

D'Amico, V., and D. Albarello (2008). SASHA: A Computer Program to Assess Seismic Hazard from Intensity Data, Seismol. Res. Lett., 79 (5), 663-671.

Dercourt, J., L.E. Ricou and B. Vrielynck, eds. (1993). Atlas Tethys Palaeoenvironmental Maps, Paris, Gau-
thier-Villars.

Ekström, G., and M. Nettles (2013). Global CMT web page; http:/ / www.gloabalcmt.org/ (accessed April 17, 2014).

Erdik, M., T. Rashidov, E. Safak and A. Turdukulov (2005). Assessment of seismic risk in Tashkent, Uzbekistan and Bishkek, Kyrgyz Republic, Soil Dyn. Earthq. Eng., 25, 473-486.

Faenza, L., W. Marzocchi and E. Boschi (2003). A nonparametric hazard model to characterize the spatio-temporal occurrence of large earthquakes; an application to the Italian catalogue, Geophys. J. Int., $155,521-531$.

Frankel, A. (1995). Mapping seismic hazard in the central and eastern United States, Seismol. Res. Lett., 66 (4), 8-21.

Gardner, J.K., and L. Knopoff (1974). Is the sequence of earthquakes in Southern California, with aftershocks removed, Poissonian?, B. Seismol. Soc. Am., 64, 1363-1367.

Ghose, S., M.W. Hamburger and C.J. Ammon (1998). Source parameters of moderate-sized earthquakes in the Tien Shan, Central Asia from regional moment tensor inversion, Geophys. Res. Lett., 25, 3181-3184.

Giardini, D. (1999). The Global Seismic Hazard Assessment Program (GSHAP) - 1992/1999, Annali di Geofisica, 42 (6), 957-974.

Gómez , J.B., and A.F. Pacheco (2004). The Minimalist Model of characteristic earthquakes as a useful tool for description of the recurrence of large earthquakes, B. Seismol. Soc. Am., 94, 1960-1967.

Gorshkov, G.P. (1937). The seismic map of the USSR, Bol'shoysovietskiy Atlas Mira, Moscow, 1, 93 (in Russian).

Gutenberg, B., and C.F. Richter (1944). Frequency of earthquakes in California, B. Seismol. Soc. Am., 34 (4), 185-188.

Herrmann, R.B. (1977) Recurrence relations, Earthquake notes, 48, 47-49.

Holt, W.E., R.N. Chamot, X. Le-Pichon, A.J. Haines, T.B. Shen and J. Ren (2000). Velocity field in Asia inferred from Quaternary fault slip rates and Global Positioning System observations, J. Geophys. Res., 105, 19185-19209.

Kagan, Y.Y., and D.D. Jackson (2000). Probabilistic forecasting of earthquakes, Geophys. J. Int., 143, 438-453.

Karnik, V. (1968). Seismicity of the European Area. Part 1. Catalogue of earthquakes (1901-1955), Publishing house of the Czechoslovak Academy of Science.

Kondorskaya, N.V., and N.V. Shebalin, eds. (1982). New Catalogue of strong earthquakes in the USSR from Ancient Times through 1975, 2nd ed., Boulder, Col- 
orado, 608 pp.

Kondorskaya, N.V., and V.I. Ulomov (1996). Specialized earthquake catalogue for seismic zoning of Northern Eurasia, Main achievements of the Joint Institute of Physics of the Earth named after Schmidt O. Yu. for 1992-1996, Moscow, JIPE, 1, 108-109.

Kyurskeyev, A., A. Nurmagambetov, A. Sydykov, N.N. Mikhailova and V.I. Shatsilov (1993). Detailed seismic zoning of Almaty industrial area, NovostinaukiKazakhstana, Alma-Ata, Issue 1.

Lukk, A.A., S.L. Yunga, V.I. Shevchenko and M.W. Hamburger (1995). Earthquake focal mechanisms, deformation state, and seismotectonics of the Pamir, Tien Shan region, Central Asia, J. Geophys. Res., 100 (B10), 20321-20343; doi:10.1029/95JB02158, ISSN 0148-0227.

McGuire, R.K. (1976). FORTRAN computer program for seismic risk analysis, U.S. Geological Survey, Open-File Report, 76-67.

McGuire, R.K. (2004). Seismic Hazard and Risk Analysis, EERI Publications, Earthquake Engineering Research Institute, Oakland, CA, $240 \mathrm{pp}$.

Medvedev, S., W. Sponheuer and V. Kárník (1964). NeueseismischeSkala Intensity scale of earthquakes, 7.Tagung der Europäischen Seismologischen Kommission vom 24.9. bis 30.9.1962, In: Jena, Veröff. Institut für Bodendynamik und Erdbebenforschung in Jena, Deutsche Akademie der Wissenschaften zu Berlin, 77, 69-76.

Mikhailova, N.N., and V. Kurskeev (1995). Present status of the network for seismic observation in Kazakhstan, J. Earthq. Prediction Res., 4 (4), 497-506.

Mikhailova, N.N. (1996). Seismic hazard in quantity characteristics of strong ground motions (on the example of Almaty), Doctoral dissertation on Physics and Mathematics.

Mikhailova, N.N., A.S. Mukambayev, I.L. Aristova, G. Kulikova, S. Ullah, M. Pilz and D. Bindi (2015). Central Asia earthquake catalogue from ancient time to 2009, Annals of Geophysics, 58 (1), S0102; doi:10.44 01/ag-6681.

Molina, S., C.D. Lindholm and H. Bungum (2001). Probabilistic seismic hazard analysis: zoning free versus zoning methodology, B. Geofis. Teor. Appl., 42 (1/2), 19-39.

Molnar, P., and P. Tapponnier (1975). Cenozoic tectonic of Asia: Effects of a continental collision, Science, 189 (4201).

Molnar, P., and P. Tapponnier (1978). Active tectonics of Tibet, J. Geophys. Res., 83, 5361-5375.

Mushketov, I.V, and A.P. Orlov (1893). Catalogue of earthquakes of Russian Empire (KatalogzemletryaseniyRossiyskoilmperii), Notes of Russian Geographic
Soc., St. Peterburg, 26, 582 pp. (in Russian).

Mushketov, D.I. (1933). Opyt seysmicheskogo rayonirovanija S.S.S.R. Tr. Seismol.Inst. Akad. Nauk S.S.S.R., 33, 1-17.

Musson, R.M.W. (1999) Probabilistic seismic hazard maps for the North Balkan region, Annali di Geofisica, 42 (6), 1109-1124

Musson, R.M.W. (2005). Intensity attenuation in the UK, J. Seismol., 9, 73-86.

Nelson, M.R., R. McCaffrey and P. Molnar (1987). Source parameters for 11 earthquakes in the Tien Shan, Central Asia, determined by $\mathrm{P}$ and $\mathrm{SH}$ waveform inversion, J. Geophys. Res., 92, 12629-12648.

Nurmagambetov, A., N. Mikhailova and W. Iwan (1999). Seismic hazard of the Central Asia region, In: S.A. King, V.I. Khalturinand and B.E. Tucker (eds.), Seismic hazard and building vulnerability in post-Soviet Central Asian republics, Kluwer Academic Publishers, Nederlands, 1-43.

Otto, S.C. (1997). Mesozoic-Cenozoic history of deformation and petroleum systems in sedimentary basins of Central Asia: implications of collisions on the Eurasian margin, Pet. Geosci., 3, 327-341.

Pagani, M., D. Monelli, G. Weatherill, L. Danciu, H. Crowley, V. Silva, P. Henshaw, L. Butler, M. Nastasi, L. Panzeri, M. Simionato and D. Viganò (2014). OpenQuake Engine: An Open Hazard (and Risk) Software for the Global Earthquake Model, Seismol. Res. Lett., 85 (3), 692-702.

Patriat, P., and J. Achache (1984). India-Eurasia collision chronology has implications for crustal shortening and driving mechanisms of plates, Nature, 31 (1), 615-621.

Rautian, T., and W. Leith (2002). Composite Regional Catalogs of Earthquakes in the Former Soviet Union, U.S. Geological Survey, Open File Report 02-500.

Rautian, T., V. Khalturin, K. Fujita, K. Mackey and A. Kendall (2007). Origins and methodology of the Russian energy K-class system and its relationship to magnitude scales, Seismol. Res. Lett., 78, 579-590.

Reiter, L. (1990). Earthquake Hazard Analysis, Columbia University Press, New York.

Riznichenko, J.V. (1959). On quantitative determination and mapping of seismic activity, Annals of Geophysics, 12 (2).

Riznichenko, Y. (1966). Calculation of ground shaking of the surface points caused by earthquakes in adjustment area, Physics of the Earth, 5, 2-32.

Schurr, B., L. Ratschbacher, C. Sippl, R. Gloaguen, X. Yuan and J. Mechie (2014). Seismotectonics of the Pamir, Tectonics, 33 (8), 1501-1518.

Simpson, D.W., and W. Leith (1985). The 1976 and 1984 Gazli, USSR, earthquakes - Were they induced?, B. 
Seismol. Soc. Am., 75 (5), 1465-1468.

Stepp, J.C. (1973). Analysis of completeness of the earthquake sample in the Puget Sound area, In: Harding S.T. (ed.), Seismic zoning, NOAATech Report ERL 267-ESL30, Boulder, CO.

Stock, C., and E.G.C. Smith (2002). Adaptive kernel estimation and continuous probability representation of historical earthquake catalogs, B. Seismol. Soc. Am., 92 (3), 904-912.

Tapponnier, P., and P. Molnar (1979). Active faulting and Cenozoic tectonics of the Tien Shan, Mongolia, and Baykal regions, J. Geophys. Res., 84, 3425-3459.

Tapponnier, P., M. Mattauer, F. Proust and C. Cassaigneau (1981). MessozoicOphiolites, Sutures and large scale tectonic movements in Afghanistan, Earth Planet. Sc. Lett., 52, 355-371.

Tatevossian, R. (2004). History of earthquake studies in Russia, Annals of Geophysics, 47 (2/3), 811-830.

Trifonov, V.G. (1996). World map of active faults in Eurasia: principles, methods and results, J. Earthq. Prediction Res., 5, 326-347.

Tselentis, G., and L. Danciu (2008). Empirical relationships between Modified Mercalli Intensity and engineering ground motion parameters in Greece, B. Seismol. Soc. Am., 98 (4), 1863-1875.

Uhrhammer, R. (1986). Characteristics of Northern and Central California Seismicity, Earthquake Notes, $57,21$.

Ullah, S., D. Bindi, M. Pilz and S. Parolai (2015). Probabilistic seismic hazard assessment of Bishkek, Kyrgyzstan, considering empirically estimated site effects, Annals of Geophysics, 58 (1), S0105; doi:10.4401/ag6682.

Ulomov, V.I., and the GSHAP Region 7 Working Group (1999). Seismic hazard of Northern Eurasia, Annali di Geofisica, 42 (6), 1023-1038.

Van Stiphout, T., J. Zhuang and D. Marsan (2012). Seismicity declustering, Community online resource for statistical seismicity analysis; doi:10.5078/corssa52382934, available at http: / / www.corssa.org.

Weatherill, G.A. (2014) OpenQuake Hazard Modeller's Toolkit - User Guide, Global Earthquake Model (GEM), Technical Report.

Weichert, D.H. (1980). Estimation of earthquake recurrence parameters for unequal observation periods for different magnitudes, B. Seismol. Soc. Am., 70, 1337-1356.

Wiemer, S., D. Giardini, D. Fäh, N. Deichmann and S. Sellami (2009). Probabilistic seismic hazard assessment of Switzerland: best estimate and uncertainties, J. Seismol., 13, 449-478.

Woo, G. (1996). Kernel estimation methods for seismic hazard area source modeling, B. Seismol. Soc. Am.,
86 (2), 353-362.

Zonenshain, L., M.I. Kuzmin and L.M. Natapov (1990). Geology of the U.S.S.R.: A Plate Tectonic Synthesis, American Geophysical Union, Geodynamics Series, 21, 1-242.

Zubovich, A.V., X. Wang, Y.G. Scherba, G.G. Schelochkov, R. Reilinger, C. Reigber, O.I. Mosienko, P. Molnar, W. Michajljow, V.I. Makarov, J. Li, S.I. Kuzikov, T.A. Herring, M.W. Hamburger, B.H. Hager, Y. Dang, V.D. Bragin and R.T. Beisenbaev (2010). GPS velocity field for the Tien Shan and surrounding regions, Tectonics, 29; doi:10.1029/2010TC002772, ISSN 0278-7407.
${ }^{\star}$ Corresponding author: Shahid Ullah, Helmholtz Center Potsdam - German Research Center for Geosciences, Potsdam, Germany; email: ullah@gfz-potsdam.de.

C 2015 by the Istituto Nazionale di Geofisica e Vulcanologia. All rights reserved. 